\title{
Hydrometeorological multi-model ensemble simulations of the 4 November 2011 flash flood event in Genoa, Italy, in the framework of the DRIHM project
}

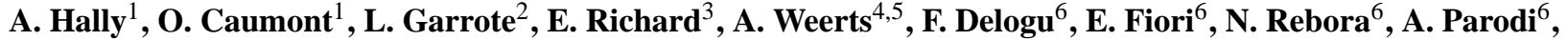 \\ A. Mihalović ${ }^{7}$, M. Ivković ${ }^{7}$, L. Dekić ${ }^{7}$, W. van Verseveld ${ }^{4}$, O. Nuissier ${ }^{1}$, V. Ducrocq ${ }^{1}$, D. D'Agostino ${ }^{8}$, A. Galizia ${ }^{8}$, \\ E. Danovaro ${ }^{8}$, and A. Clematis ${ }^{8}$ \\ ${ }^{1}$ CNRM-GAME (Météo-France, CNRS) Toulouse, France \\ ${ }^{2}$ Technical University of Madrid, Madrid, Spain \\ ${ }^{3}$ Laboratoire d'Aérologie, Université de Toulouse and CNRS, Toulouse, France \\ ${ }^{4}$ Deltares, Delft, the Netherlands \\ ${ }^{5}$ Hydrology and Quantitative Water Management Group, Department of Environmental Sciences, Wageningen University, \\ Wageningen, the Netherlands \\ ${ }^{6}$ CIMA Research Foundation, Savona, Italy \\ ${ }^{7}$ Republic HydroMeteorological Service of Serbia, Belgrade, Serbia \\ ${ }^{8}$ Inst. of Applied Mathematics and Information Technology - Consiglio Nazionale delle Ricerche, Genoa, Italy
}

Correspondence to: A. Hally (alan.hally@meteo.fr)

Received: 30 September 2014 - Published in Nat. Hazards Earth Syst. Sci. Discuss.: 3 November 2014

Revised: 20 February 2015 - Accepted: 23 February 2015 - Published: 12 March 2015

\begin{abstract}
The e-Science environment developed in the framework of the EU-funded DRIHM project was used to demonstrate its ability to provide relevant, meaningful hydrometeorological forecasts. This was illustrated for the tragic case of 4 November 2011, when Genoa, Italy, was flooded as the result of heavy, convective precipitation that inundated the Bisagno catchment. The Meteorological Model Bridge (MMB), an innovative software component developed within the DRIHM project for the interoperability of meteorological and hydrological models, is a key component of the DRIHM e-Science environment. The MMB allowed three different rainfall-discharge models (DRiFt, RIBS and HBV) to be driven by four mesoscale limited-area atmospheric models (WRF-NMM, WRF-ARW, Meso-NH and AROME) and a downscaling algorithm (RainFARM) in a seamless fashion. In addition to this multi-model configuration, some of the models were run in probabilistic mode, thus giving a comprehensive account of modelling errors and a very large amount of likely hydrometeorological scenarios $(>1500)$.
\end{abstract}

The multi-model approach proved to be necessary because, whilst various aspects of the event were successfully simulated by different models, none of the models reproduced all of these aspects correctly. It was shown that the resulting set of simulations helped identify key atmospheric processes responsible for the large rainfall accumulations over the Bisagno basin. The DRIHM e-Science environment facilitated an evaluation of the sensitivity to atmospheric and hydrological modelling errors. This showed that both had a significant impact on predicted discharges, the former being larger than the latter. Finally, the usefulness of the set of hydrometeorological simulations was assessed from a flash flood early-warning perspective.

\section{Introduction}

In the Mediterranean region, flash floods are the natural hazards which lead to the greatest economic losses (Llasat et al., 2013). These flash floods are the result of heavy precipitation falling over small-to-medium-size catchments in the 
mountainous regions located along the Mediterranean coastline. Although such hydrometeorological phenomena have been studied quite extensively, timely and accurate prediction of flash floods still remains a challenge. For smallto-medium-size catchments, rainfall-discharge hydrological models are appropriate, acknowledged tools to forecast flash floods. Given the short hydrological response times of these catchments, it is necessary to use quantitative precipitation forecasts instead of single observations to drive these hydrological models in order to enhance the forecast lead times (Melone et al., 2005).

In recent decades, tremendous progress has been made in developing flood forecasting systems (e.g. Werner et al., 2013) and many operational centres employ complex systems that combine hydrologic/hydraulic models with either or both deterministic and ensemble meteorological forecasts. This progress started in the 1990s when meteorological ensemble forecasts (e.g. at the European-Centre for Medium-Range Weather Forecasts (ECMWF), Houtekamer et al., 1996; the National Center for Environmental Prediction (NCEP), Molteni et al., 1996; and Météo-France, Descamps et al., 2014) became available and used as rainfall sources for flood forecasting (e.g. Cloke and Pappenberger, 2009; Price et al., 2012). For instance, EU FP5 projects like EFFS (Pappenberger et al., 2005) showed the applicability and usefulness of the ensemble approach for hydrological forecasting. Since then, many EU and other collaborative research projects focusing on this topic, such as HEPEX (Schaake et al., 2007) and MAP-D-Phase (Rotach et al., 2009) have been, and are being, conducted. Concurrently, the research efforts of Davolio et al. (2013), Vincendon et al. (2011) and Rebora et al. (2006) demonstrated the improvement in flood forecasting brought about through the use of convection-resolving horizontal resolutions in the meteorological model rainfall sources and also illustrated the advantages of perturbing model parameters and rainfall sources, and in employing the dynamical downscaling of a large-scale ensemble prediction system (EPS). Other research projects resulted in the development of ensemble flood forecasting systems such as EFAS (Thielen et al., 2009), FEWS Rivieren (Renner et al., 2009; Verkade et al., 2013) and FFC (Price et al., 2012) (see Cloke and Pappenberger (2009) for a general review of ensemble flood forecasting). The results, models (code and regional configurations) and historical/forecast workflows used in such research are often not accessible (e.g. due to licences) or not easily accessible (e.g. requiring heavy computer resources) for academic research or research conducted by citizen scientists. However, basic academic research requires that experiments can be repeated and results can be reproduced.

The European Commission Seventh Framework Programme (FP7) Distributed Research Infrastructure for Hydro-Meteorology (DRIHM) project (2011-2015) aims to utilise state-of-the-art information and communication technology to address these issues. More specifically, a prototype
e-Science environment was developed in the framework of this project, which allows various users (researchers, citizen scientists) to provide and access hydrometeorological data and models and run complex hydrometeorological chains via a user-friendly interface. The DRIHM Distributed Computing Infrastructure (DDCI) is designed to be flexible, extensible and interoperable. As such, it seamlessly integrates an extensible set of heterogeneous models, computing resources and advanced services by relying on existing and emerging standards. A science gateway, the DRIHM Portal (http://portal.drihm.eu/), allows the user to access the DDCI through the configuration of hydrometeorological workflows to be executed on resources such as supercomputers, grid and cloud facilities. The specific workflows that are considered in the framework of DRIHM include a large panel of modelling resources ranging from atmospheric to hydraulic models through rainfall-discharge hydrological models. This article focuses solely on the demonstration of the DRIHM e-Infrastructure's usefulness in studying flash flood forecasting for early-warning applications. Thus, only a description of atmospheric and hydrological models available from the DRIHM e-Infrastructure and how they are coupled is provided hereafter. More technical details regarding the DRIHM e-Infrastructure can be found in D'Agostino et al. (2014), Danovaro et al. (2014) and Galizia et al. (2014), while additional information concerning DRIHM can be found at the following web page: http://www.drihm.eu/.

The case study of the Genoa flash flood, which took place on 4 November 2011, was chosen to test a hydrometeorological ensemble strategy. Section 2 gives a description of the meteorological situation which led to this flash flood event. This is followed by details of the different meteorological and hydrological models in Sect. 3 along with an explanation of the hydrometeorological modelling chain. The results of the hydrometeorological simulations, both deterministic and ensemble, are outlined in Sect. 4, while the article's conclusions are detailed in Sect. 5 .

\section{The 4 November 2011 Genoa flash flood event}

The extreme rainfall event that took place in Genoa on 4 November 2011 generated a severe flash flood that led to the loss of six lives. Rain gauges on the territory surrounding the city, which is situated between the Tyrrhenian Sea and the Apennine Mountains (Liguria, Italy), recorded approximately $500 \mathrm{~mm}$ of rain in $6 \mathrm{~h}$ (see Fig. 1).

The convective system which led to this heavy precipitation event (HPE) was associated with a synoptic-scale disturbance that was present over the Atlantic Ocean in the preceding days (Rebora et al., 2013). A deep and cold upperlevel trough was present to the north-west of Ireland in the early hours of 4 November (see Fig. 2a). This led to a southwesterly mid-tropospheric flow over the target area and a south to south-easterly low-level flow bringing warm moist 


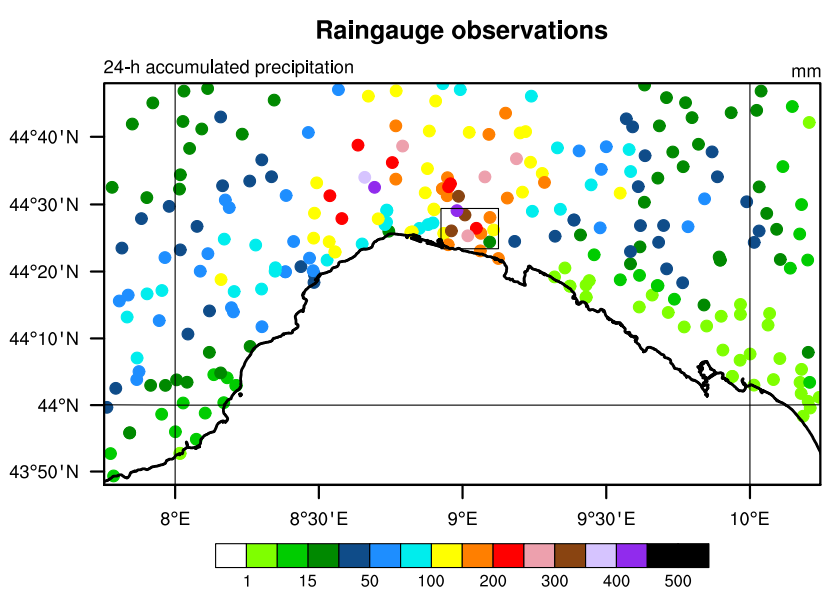

Figure 1. $24 \mathrm{~h}$ observed rainfall amounts for the Liguria region between 00:00 UTC on 4 November and 00:00 UTC on 5 November 2011. The Bisagno region is highlighted by the black rectangle.

air towards the Ligurian coasts (see Fig. 2b). Locally these conditions caused the development of a self-regenerating mesoscale convective system (MCS), which was triggered in the Gulf of Genoa between 01:00 and 02:00 UTC. The lowlevel convergence line responsible for the MCS was born out of the interaction of cold air coming from the northnorthwest towards the central-western part of the Gulf of Genoa, and warm moist air streaming in from the south-east towards Italian coastlines. The MCS moved slowly along the Ligurian coast as the night progressed into day (Fig. 3, left panel), and finally stalled over the western part of the Genoese hills towards 11:00 UTC. This led to a very intense but localised convective rainfall rate over the Bisagno basin around 12:00 UTC, clearly visible on the radar reflectivities presented in Fig. 3 (middle panel). One ground station observed almost $170 \mathrm{~mm}$ in one hour. The system then moved westwards as the day progressed, leading to a secondary rainfall peak to the west of Bisagno around 18:00 UTC (Fig. 3, right panel). A more complete and detailed description of the situation can be found in Rebora et al. (2013), Buzzi et al. (2014) and Fiori et al. (2014).

\section{Modelling tools and numerical setups}

A combination of precipitation and hydrological discharge simulations was employed to recreate the Genoa flash flood event. This was done through the use of convectionpermitting limited-area meteorological models, the quantitative precipitation forecasts of which were used to drive hydrological models, which in turn simulated discharge forecasts at the outlet of the Bisagno river. In the following, the meteorological models and the numerical setups used in this study are presented. A visualisation of the domains is given in Fig. 4. Following this, the hydrological models are also introduced. At the end of this section, the DRIHM
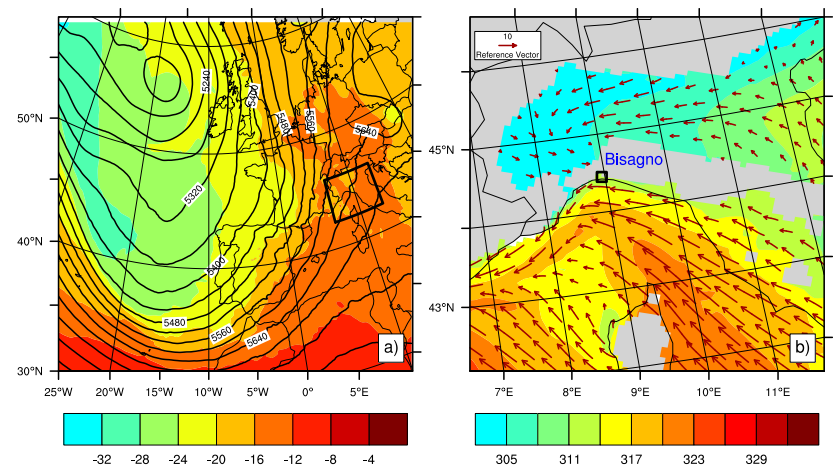

Figure 2. ECMWF large-scale analysis at 00:00 UTC on 4 November 2011 showing (a) temperature $\left({ }^{\circ} \mathrm{C}\right)$ and geopotential height $(\mathrm{m})$ at $500 \mathrm{hPa}$ and $(\mathrm{b})$ equivalent potential temperature $(\mathrm{K})$ and winds $\left(\mathrm{m} \mathrm{s}^{-1}\right)$ at $950 \mathrm{hPa}$. The black rectangle on (a) represents the interested region (plotted in b), covering Liguria in north-western Italy. The shaded areas represent orographic regions. The position of the Bisagno water basin is included for reference on (b).

e-infrastructure is presented, which allows any hydrological model to be driven by any meteorological model.

\subsection{Meteorological models}

This section details the specificities of the WRF-NMM, WRF-ARW, Meso-NH, AROME and RainFARM models which are in use within the DRIHM project. All models are run at kilometric scale resolutions. Although they may be initialised at different times, their forecasts all cover the period of time between 00:00 UTC on 4 November and 00:00 UTC on 5 November. The domains, initial (IC) and boundary (BC) conditions and model physics differ between each model as is described hereafter.

\subsubsection{WRF-NMM}

The Weather Research and Forecasting (WRF) system is a numerical weather prediction system developed in cooperation with the National Center for Atmospheric Research (NCAR) and NCEP in the USA. Two versions of the model exist, differing in the description of their dynamical cores. One version is known as WRF-NMM, for WRFNon-hydrostatic Mesoscale Model. This version of WRF presents an alternative approach to non-hydrostatic modelling, whereby the hydrostatic model has been extended to include the non-hydrostatic motions, thus preserving the favourable features of the hydrostatic formulation. However, the model is classified as non-hydrostatic.

The vertical coordinate in the NMM model is the terrain following hybrid pressure-sigma coordinate. Sigma is the vertical mass (hydrostatic pressure) based coordinate. The map projection in the NMM model is latitude-longitude coordinates rotated in a way that the coordinate origin is located in the centre of the integration domain and translated in the 

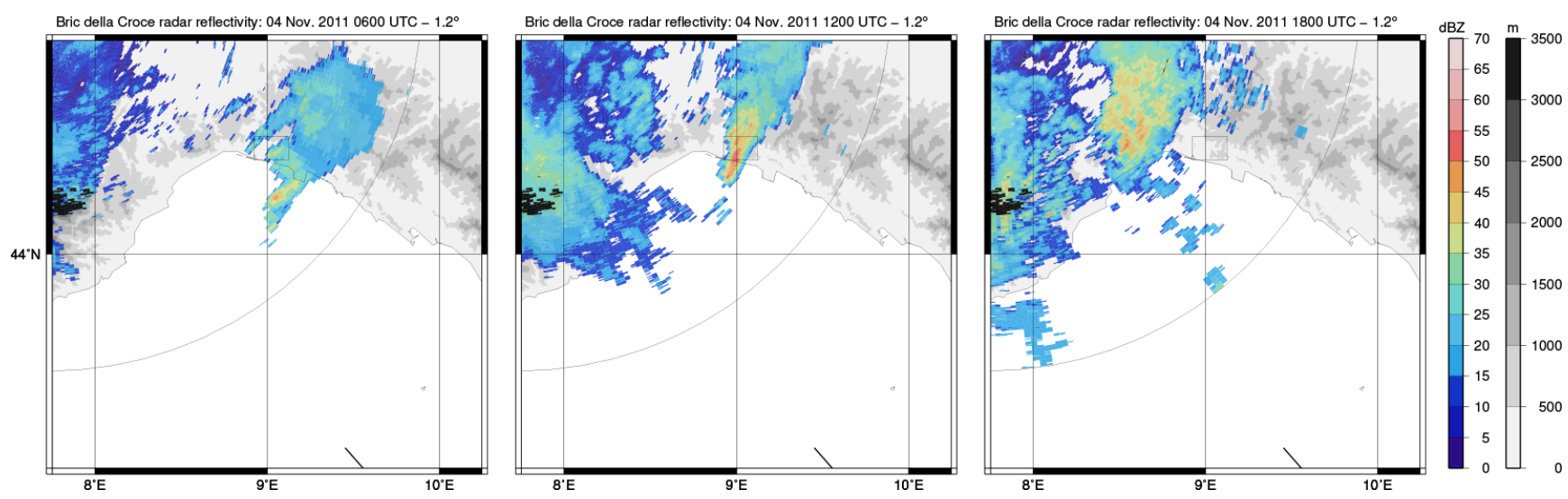

Figure 3. The radar reflectivities (colour shades) superimposed on the orography (grey shades) from the Bric della Croce radar at 06:00 UTC (left panel), 12:00 UTC (middle panel) and 18:00 UTC (right panel) on 4 November 2011. The black pixels correspond to ground clutter.

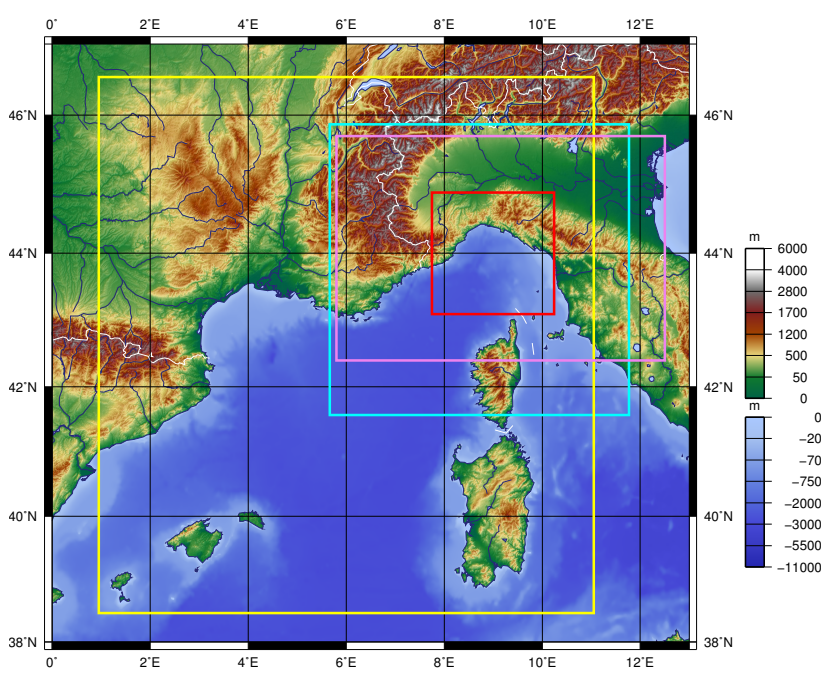

Figure 4. Map showing the location of the interested zone. The innermost domains of the simulations for the different models are WRF-NMM (pink), WRF-ARW (blue), Meso-NH (red) and AROME (yellow).

intersection of the equator and prime meridian. The grid staggering is the semi-staggered Arakawa E-grid.

The discretisation applied in the NMM model was tested in the earlier hydrostatic model Eta. A detailed description of the model dynamics can be found in Janjic et al. (2001); Janjic (2003). The same time step is used for all terms. A number of first and second order quantities, including energy and enstrophy, are conserved.

For the simulations carried out within the DRIHM project, the WRF-NMM model employed the Thompson (Thompson et al., 2008) microphysical parameterisation scheme, the long-wave radiation parameterisation known as RRTM (Mlawer et al., 1997), a short-wave radiation parameterisation according to Goddard (Chou and Suarez, 1999) and a surface-layer scheme following Janjic (Janjic, 1996a, b).
The land-surface scheme was described according to the NOAH LSM scheme (Niu et al., 2011), while the boundarylayer and cumulus convection were parameterised following the schemes of Mellor-Yamada-Janjic (Janjic, 2003) and Betts-Miller-Janjic (Janjic, 1994; Betts and Miller, 1993), respectively.

The horizontal resolution of the parent domain for the Genoa case was $4 \mathrm{~km}(220 \times 290$ points $)$, while for the nested domain it was $1.33 \mathrm{~km}(295 \times 412$ points) (pink domain in Fig. 4), without the cumulus parameterisation. Here only the innermost domain at a $1.33 \mathrm{~km}$ resolution is reported upon. There were 45 vertical levels and 4 soil layers. IC and BC for the outermost domain were taken from the Integrated Forecasting System (IFS) model of the European Centre for Medium-range Weather Forecasts (ECMWF) with the BC being upgraded every $3 \mathrm{~h}$. Each WRF-NMM simulation ran from 00:00 UTC on 4 November to 00:00 UTC on 5 November.

\subsubsection{WRF-ARW}

The second version of WRF used in this study is known as the Advanced Research WRF (ARW) dynamical core, and is supported by the Mesoscale and Microscale Meteorology Division at NCAR. A fully compressible and non-hydrostatic set of equations is employed, which is integrated in time by applying a third-order Runge-Kutta scheme while the spatial discretisation employs 2 nd to 6 th order schemes. The vertical coordinates are described using a terrain-following, hydrostatic-pressure system and the horizontal grid is an Arakawa-C grid.

For the Genoa case simulations, a domain with a horizontal resolution of $1 \mathrm{~km}$ and no cumulus parameterisation (blue domain shown in Fig. 4), was nested inside a parent domain of $5 \mathrm{~km}$ horizontal resolution. For the innermost domain, 83 vertical levels were chosen, with several thin layers used close to the surface in order to more ac- 
curately distinguish the low-level circulation and dynamics over the complex topography of the region. The boundary layer was parameterised according to the Yonsei University (YSU) scheme (Hong et al., 2006) while a Monin-Obukhovinspired surface-layer scheme (Janjic, 1996b) was chosen. The land-surface scheme implemented was the simple soil thermal diffusion scheme. Following the results of a series of preliminary tests on the cumulus parameterisations, it was seen (not shown) that the model performed most accurately when convection was explicitly represented at both $5 \mathrm{~km}$ and $1 \mathrm{~km}$ horizontal resolution. The microphysics, long-wave and short-wave radiation parameterisation choices, along with the IC and BC (updated every $3 \mathrm{~h}$ ) of the parent domain and the simulation time period, followed those of the WRFNMM simulation.

\subsubsection{Meso-NH}

Meso-NH (Lafore et al., 1998) is a non-hydrostatic mesoscale atmospheric model that was developed by the Laboratoire d'Aérologie and CNRM-GAME. The model is based on an advanced set of anelastic systems. The prognostic variables are the three Cartesian components of velocity, the dry potential temperature, the six water mixing ratios (water vapour, cloud water, rain water, primary ice, snow aggregates, and graupel) and the turbulent kinetic energy (TKE). A conformal projection is used in the horizontal while the vertical coordinate is that of Gal-Chen and Somerville (1975). For the Genoa case, Meso-NH was run on a single square domain $(400 \times 400$ grid points, red square in Fig. 4) at the horizontal resolution of $500 \mathrm{~m}$. The model was run with a 3-D turbulence parameterisation with Deardorff mixing length (Cuxart et al., 2000). Radiation transfer was modelled by the Rapid Radiative Transfer Model (RRTM) (Mlawer et al., 1997). The surface scheme was ISBA (Interactions Soil-Biosphere-Atmosphere scheme) (Noilhan and Mafhouf, 1996) and energy exchanges over urban surfaces were parameterised according to the Town Energy Balance (TEB) model (Masson, 2000). Both shallow and deep convection were disabled. The ICE3 single-moment bulk microphysical scheme (Pinty and Jabouille, 1998; Lascaux et al., 2006) was used to model microphysical processes.

Two ensembles were produced that differ by their IC and $\mathrm{BC}$ : experiments MNH-ARP were initialised and coupled every $3 \mathrm{~h}$ with Météo-France's ARPEGE global forecasts while experiments MNH-MWF were initialised and coupled every $3 \mathrm{~h}$ with IFS global forecasts. Both ensembles were initialised at 00:00 UTC on 4 November 2011. In both ensembles, the 9 perturbed members were obtained by introducing random perturbations on the turbulent and microphysical time tendencies as detailed in Hally et al. (2014b). Each ensemble had one control (CTRL) simulation where the random perturbations were not activated.

\subsubsection{AROME}

AROME is used at Météo-France to elaborate operational weather forecasts over France (Seity et al., 2011). It is a nonhydrostatic model, based on an extension of the adiabatic equations of the limited-area numerical weather prediction (NWP) model ALADIN (Bubnová et al., 1995; Bénard, 2004), that runs at a horizontal resolution of $2.5 \mathrm{~km}$ and with 60 levels in the vertical. Its physical parameterisations are the same as that used by Meso-NH in this study, except that shallow convection is parameterised (Pergaud et al., 2009) and turbulence is one-dimensional.

The AROME-EPS used within DRIHM is based on the operational version of AROME, but on a smaller domain of $365 \times 377$ grid points that covers the north-western part of the Mediterranean region (see Fig. 4, yellow square). AROME ensemble members were initialised at 18:00 UTC on 3 November, through an ensemble data assimilation technique where the analysis error is sampled by the cycled assimilation of randomly perturbed observations (every $3 \mathrm{~h}$ ), creating different IC for each of the 7 ensemble members (Vié et al., 2012). AROME members were coupled every $3 \mathrm{~h}$ with different ARPEGE-EPS (PEARP) forecasts selected through a clustering algorithm (Nuissier et al., 2012). The CTRL simulation represents the AROME simulation in its standard configuration.

\subsubsection{RainFARM}

The Rainfall Filtered AutoRegressive Model (RainFARM) (Rebora et al., 2006) is a method for the realisation of stochastic rainfall downscaling that can be easily applied to the precipitation forecasts provided by meteorological models. Due to the straightforward link between the model parameters and the large-scale field, RainFARM is able to generate small-scale rainfall fields by preserving the Limited Area Model (LAM) information at scales where meteorological prediction is trustworthy. As a consequence, in the small-scale, rainfall fields take into account not only the total amount of precipitation predicted by the meteorological model, but also its linear correlation structure and the position of the main rainfall patterns.

From a mathematical point of view, RainFARM belongs to the family of algorithms called meta-Gaussian models (see e.g. Giannoni et al., 2005) and it is based on a nonlinear transformation of a Gaussian random field. This approach is closely related to the Turning Bands Method (Matheron, 1973) and it has been used both for satellite-based rainfall measurement validation and for stochastic rainfall modelling (Bell and Kundu, 2003; Lanza, 2000). The CIMA Foundation uses the RainFARM model in the framework of its operational activities in cooperation with the Italian Civil Protection Department (ICPD) and ARPAL (Hydro-Meteo Regional Service of Liguria region). 
Here, RainFARM uses precipitation forecasts from the WRF-ARW simulation described previously to produce 20 ensemble members at a horizontal resolution of $700 \mathrm{~m}$.

\subsection{Hydrological models}

Three different hydrological models are considered in this study: RIBS, DRiFt and HBV. These models were selected due to their availability on the DRIHM platform. DRiFt and HBV are continuous simulation models and therefore they estimate the basin initial condition by applying model equations to antecedent precipitation. RIBS is an event-based model and the initial condition is specified as a probability distribution of initial states inferred from calibration. All models are run on the Bisagno catchment and forecast discharges at the catchment's outlet from 00:00 UTC on 4 November onwards. The differences between these three models are detailed in the following.

\subsubsection{DRiFt}

DRiFt, Discharge River Forecast (Giannoni et al., 2000, 2005, 2008), is a semi-distributed rainfall runoff model, based on a geomorphologic approach. It uses information and input (e.g. rainfall field, elevation and soil properties) distributed over the territory, while it is almost lumped in parameters and results. A morphologic filter, based on contributing area and local slope, is used to identify hill slope and channel paths (Roth et al., 1996). On the basis of this distinction, different typical velocities are assigned to each portion of the surface paths, either classified as hill slope or channel. In this way the hydrologic processes that take place on the different components of the system are coupled with basin morphology.

The model is tied to run in an operational forecasting chain (Silvestro et al., 2011) and it uses as input quantitative precipitation forecasts in the form of spatial and temporal matrices produced by meteorological models. This general and flexible input data structure can also be produced from satellite or ground measurements. In this way, the spatial and temporal variability of rainfall patterns and the basin heterogeneity in morphologic, geologic and anthropic characteristics are considered. DRiFt uses a digital terrain model (DTM) to estimate slopes, flow directions, channel paths and corrivation times. Moreover, the model includes in its runs a curve number map to estimate the maximum soil moisture value for each cell. On the other hand, the model is lumped in parameters: these must be considered as mean quantities describing the catchment system and its dynamic at the basin scale. All the parameters have strong physical implications, allowing an easy and controllable calibration. From these characteristics, the model is defined as a semi-distributed model.

\subsubsection{RIBS}

The Real-time Interactive Basin Simulator (RIBS) is a physically based distributed model that computes hydrologic basin responses to spatially distributed rainfall inputs (Garrote and Bras, 1995a, b). The model is largely based on detailed topographical information combined with a schematic soil characterisation. The basin representation adopts the rectangular grid of the digital elevation model (DEM), and other soil properties. Input data and state variables are also represented as data layers using the same scheme. Model philosophy is based on the idea of stressing the role of topography in the runoff generation process, but keeping model complexity within reasonable limits to allow for the real time application of flood forecasting in midsize and large basins (Mediero et al., 2012). The basic objective is to map the topographically driven evolution of saturated areas as the storm progresses. Small basins would benefit from the use of more complex models in order to adequately reproduce the observed flood hydrograph. RIBS consists of two independent modules: a runoff generation module and a surface flow routing module. The runoff generation module incorporates two types of runoff generation mechanisms: infiltration excess runoff and return flow.

A kinematic model of infiltration is used to evaluate local runoff generation in grid elements. Lateral moisture flow between elements is taken into account in a simplified way in order to obtain return flows. Surface flow routing is performed with the distributed convolution equation. The local runoff generated in every grid element is routed to the basin outlet by accounting for travel time along the drainage path. The flow path is divided into a hillslope section and a channel section, assuming constant velocities for both overland and stream flow. RIBS calibration is performed by applying the probabilistic methodology developed in Mediero et al. (2011). Three model parameters are estimated in the calibration process: parameter $f$, which controls the rate of variation of hydraulic conductivity with depth; parameter $C_{v}$, which represents the stream velocity, and parameter $K_{v}$, which represents the ratio between stream and overland flow velocity. The result of the calibration process is the estimation of the probability distribution functions of model parameters. RIBS may be run in deterministic or probabilistic mode. In deterministic mode, only one realisation is run, with single values of model parameters. In probabilistic mode, several realisations are run, sampling parameter values from their probability distribution.

\subsubsection{HBV}

The Hydrologiska Byráns Vattenbalansavdelning (HBV) model is a conceptual semi-distributed hydrological model that was developed in the early 1970s by the Swedish Meteorological and Hydrological Institute (SMHI) (Bergström, 1976). In the early 1990s a comprehensive re-evaluation of 
the HBV model routines was carried out (Lindstrom et al., 1997), which resulted in the HBV-96 version. In this study the WFLOW-HBV model is used for modelling the Genoa flash flood. This hydrological model is based on the HBV-96 model and is part of the recently developed open source modelling environment OpenStreams (2014) (www.openstreams. $\mathrm{nl}$ ), which is suitable for integrated hydrological modelling based on the Python programming language with the PCRaster spatial processing engine (Karssenberg et al., 2009, http: //pcraster.geo.uu.nl/pcraster-4-0-0). The advantage of using OpenStreams is that it enables direct communication with OpenDA (2014) (www.openda.org.), an open source data assimilation toolbox. OpenDA provides a number of algorithms for model calibration and assimilation which renders it suitable for connection to any kind of environmental model (e.g. Ridler et al., 2014).

The WFLOW-HBV model (one of the hydrologic models available in OpenStreams) requires (gridded) time series of precipitation, temperature and potential evaporation as input data. Besides dynamic data, static input data such as a DEM, land cover map, soil map and model parameters per soil and/or land use type are required. For each of the WFLOW-HBV grid cells, the water balance and resulting runoff is computed. The model consists of three routines: a snow routine, a soil routine and a runoff response routine. The specific runoff is routed by a kinematic wave approach. For more details on the HBV-96 model see Rakovec et al. (2014) or www.openstreams.nl.

For the Genoa flash flood, a WFLOW-HBV model was set-up with an hourly time step. The river network was derived from the OpenStreams preprocessing functions using spatial data extracted from SRTM 3 arc-second resolution DEMs and from the GLC2000 project. The final grid size of the WFLOW-HBV model is $0.001^{\circ}$ latitude/longitude. Precipitation data was available from 24 precipitation stations and one hydrological station, Passarella Firpo. Temperature data were available from only four stations. The measured data was interpolated to grids using Thiessen polygons. Since measured data for potential evapotranspiration was not available, monthly mean values were calculated with Penman's formula and used as input for the model of the Bisagno river basin. In order to perform the forecast, use was made of hourly model outputs converted to the same grid format as the WFLOW-HBV model of the Bisagno river basin, using the closest distance between available values at spatially distributed locations. Dynamic input data for the model were available for periods from 2006 onwards. Continuous time series were available for calibration and verification from December 2006 until June 2011.

\subsection{Hydrometeorological modelling chains}

None of the meteorological and hydrological models considered here provide standard interfaces to pass information from one to another. This seriously hampers the devel- opment of any multi-model hydrometeorological ensemble with a substantial number of different models. To deal with this problem, a component named Meteorological Model Bridge (MMB), which ingests data structured around model grids or meshes into other models, has been designed within the DRIHM project. The MMB allows the creation of a link between meteorological model forecast outputs and other models, thus enabling chains of hydrometeorological workflows to be generated. Starting from meteorologically gridded outputs produced by meteorological models such as those mentioned in Sect. 3.1, the MMB provides usable data files in a standardised format with the twofold aim of supporting intra-model interoperability during workflow execution and organising model data in an easy and more manageable way.

The MMB converts the output of each meteorological model from its original projection to a regular latitudelongitude grid. The MMB output files contain the variables necessary to correctly drive the hydrological models, including: total accumulated surface precipitation, $2 \mathrm{~m}$ air temperature, $2 \mathrm{~m}$ specific humidity and both northward and eastward $10 \mathrm{~m}$ wind components. The standardised format chosen to be implemented in the DRIHM project is the netCDF-CF format. The Open Geospatial Consortium (OGC) netCDF encoding supports electronic encoding of geospatial data, that is, digital geospatial information representing space and time-varying phenomena. In December 2012, the CF-netCDF Data Model Extension Standard obtained a new OGC standard. This standard specifies the CF-netCDF data model extension introducing the extra semantics required to capture and formalise the metadata describing multi-dimensional gridded and multi-point data.

Since not all the subsequent models which may compose a hydrometeorological workflow in the DRIHM infrastructure are natively able to ingest netCDF-CF outputs, some extensions have been performed, when required, at the interface level of consumer modules of the different models. This allows the correct ingestion of the newly formatted data, ensuring the provision of consistent atmospheric files, and thus easily facilitating comparisons between different models (Williams et al., 2013).

\section{Results}

\subsection{Meteorological scenarios}

\subsubsection{Deterministic simulations}

CTRL simulations were performed for this case with the WRF-NMM, WRF-ARW, Meso-NH and AROME models using the configurations detailed in Sect. 3 and recalled in Table 1 . A plot of the $24 \mathrm{~h}$ simulated rainfall for each is given in Fig. 5. Both WRF simulations give large $24 \mathrm{~h}$ accumulations to the west of the Bisagno zone, but miss the most 

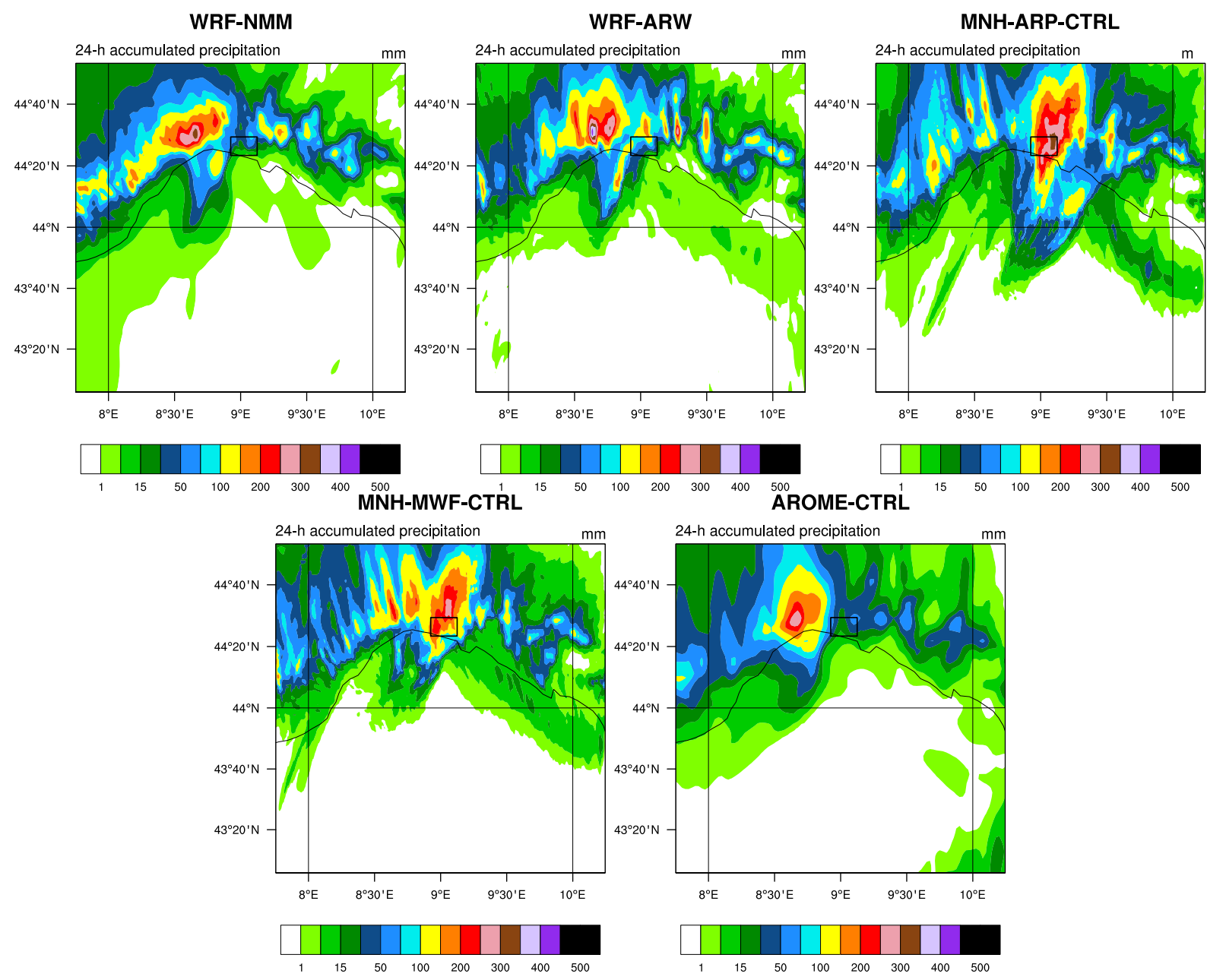

Figure 5. The $24 \mathrm{~h}$ simulated rainfall amounts (in $\mathrm{mm}$ ) of the WRF-NMM, WRF-ARW, MNH-ARP-CTRL, MNH-MWF-CTRL and AROME-CTRL simulations.

Table 1. The characteristics of the different meteorological and hydrological ensembles performed for the case of 4 November 2011 .

\begin{tabular}{|c|c|c|c|c|c|}
\hline $\begin{array}{l}\text { Rain } \\
\text { Source }\end{array}$ & Description & $\begin{array}{r}\text { No. of } \\
\text { members }\end{array}$ & $\begin{array}{l}\text { Resolution } \\
(\mathrm{km})\end{array}$ & $\begin{array}{l}\text { No. of DRiFt } \\
\text { and HBV members }\end{array}$ & $\begin{array}{r}\text { No. of RIBS } \\
\text { members }\end{array}$ \\
\hline Observations & Rain gauge measurements & 1 & $\mathrm{n} / \mathrm{a}$ & 1 & 31 \\
\hline WRF-ARW & $\mathrm{IC}+\mathrm{BC}: \mathrm{IFS}$ & 1 & 1.0 & 1 & 31 \\
\hline WRF-NMM & IC+BC: IFS & 1 & 1.3 & 1 & 31 \\
\hline AROME & IC:Pert. OBS BC: PEARP & 8 & 2.5 & 8 & 248 \\
\hline MNH-ARP & IC+BC: ARPEGE & 10 & 0.5 & 10 & 310 \\
\hline MNH-MWF & IC+BC: IFS & 10 & 0.5 & 10 & 310 \\
\hline \multirow[t]{2}{*}{ RainFARM } & Disaggregation of rain from forecast models & 20 & 0.71 & 20 & 620 \\
\hline & Total & 51 & & 51 & 1581 \\
\hline
\end{tabular}

intense precipitation peaks seen (corresponding observations plotted in Fig. 1) over the target area (displayed on the plots as a black rectangle). The AROME CTRL simulation gives a large accumulation to the west of the Bisagno zone, as in the WRF simulations, but the intensities are much less significant and most importantly, no rainfall is simulated over the regions where the largest accumulations were observed. This would have a substantial impact on the ability of the hydrological model to predict the correct inundations in the region and highlights the importance of using a multi-model or ensemble approach where numerous domains and coupling models are employed. 


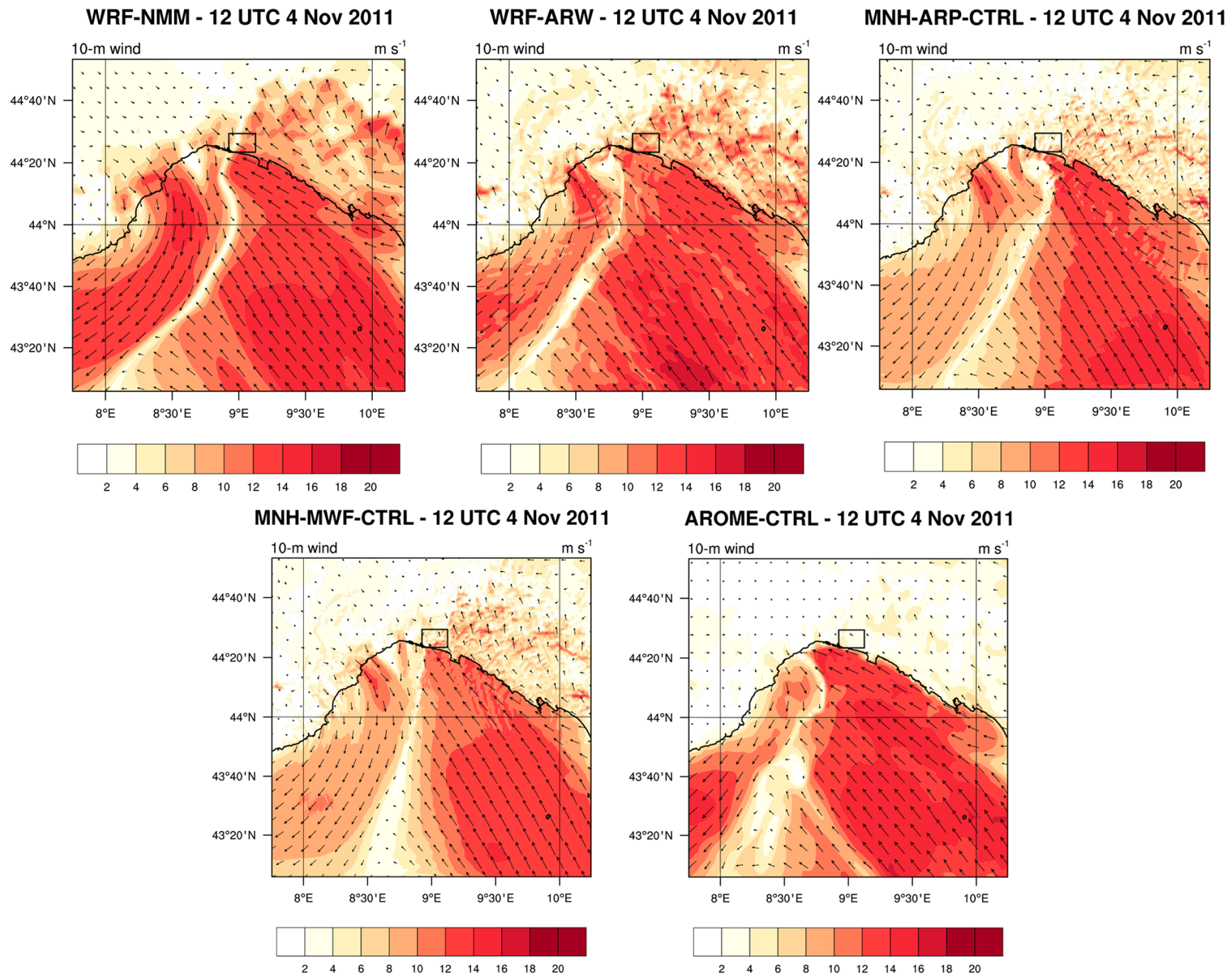

Figure 6. The $10 \mathrm{~m}$ simulated wind speeds (in $\mathrm{ms}^{-1}$ ) from the WRF-NMM, WRF-ARW, MNH-ARP-CTRL, MNH-MWF-CTRL and AROME-CTRL simulations at 12:00 UTC.

The two Meso-NH CTRL simulations (one using IC and $\mathrm{BC}$ from ARPEGE forecasts, the other using ECMWF forecasts) give much more realistic descriptions of the observed rainfall distribution. The ARPEGE forced simulation (labelled MNH-ARP) accurately simulates the location of the heaviest accumulations which were recorded in the Bisagno region. The ECMWF forced case (labelled MNH-MWF) less so, as it misses some of the larger accumulations in the east of the Bisagno zone. The WRF-ARW simulation displays the most intense rainfall, at $426 \mathrm{~mm}$ over $24 \mathrm{~h}$. This is in comparison to $346 \mathrm{~mm}$ (WRF-NMM), $300 \mathrm{~mm}$ (AROME), $336 \mathrm{~mm}$ (MNH-ARP) and $295 \mathrm{~mm}$ (MNH-MWF).

These differences in the simulated rainfall may originate from many sources, such as discrepancies in the description of the atmospheric situation between the different models. Figure 6 , showing the $10 \mathrm{~m}$ wind fields after $12 \mathrm{~h}$ of simulation, demonstrates that the MNH-ARP simulation gives the most cohesive description of the convergence line with the wind pattern over the target area in particular favouring rainfall development. The MNH-MWF simulation also illustrates the cold and warm air convergence quite well while both WRF CTRL simulations clearly describe the convergence but place it to the west of the Bisagno basin, with the south-easterly component of the wind pattern of both WRF CTRL simulations seemly influenced by the coastline. The AROME simulation describes the convective line in a much less organised manner. AROME also seems to underestimate the cold outflow coming from the Po Valley (north of the Bisagno basin). This cold outflow played an important role in the convective development (Buzzi et al., 2014), and thus an incorrect description of its characteristics greatly affected the simulated development of the convergence line and thus the MCS. 


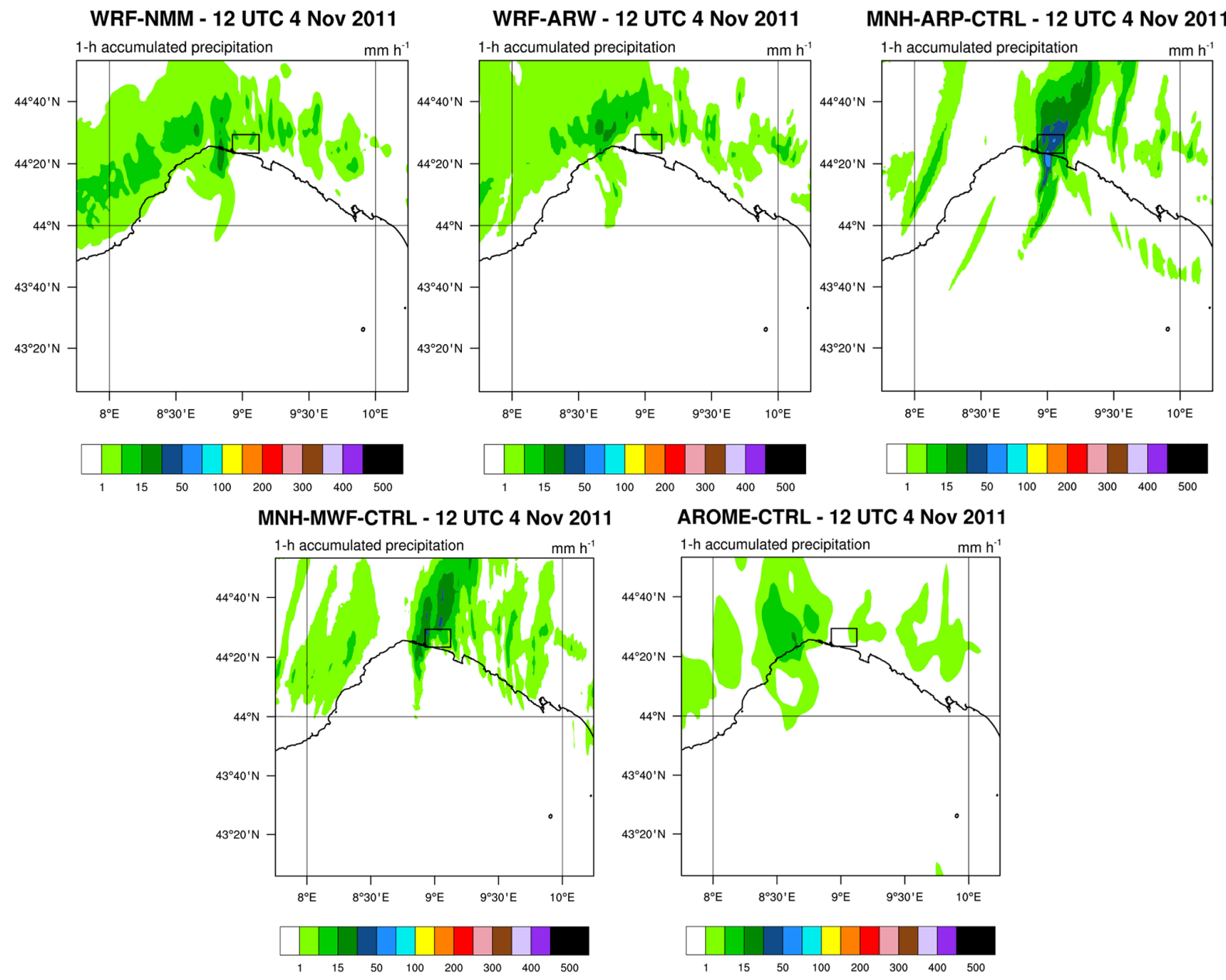

Figure 7. The $1 \mathrm{~h}$ simulated rainfall amounts (in mm) of the WRF-NMM, WRF-ARW, MNH-ARP-CTRL, MNH-MWF-CTRL and AROMECTRL simulations at 12:00 UTC.

Comparing the $1 \mathrm{~h}$ simulated rainfall accumulations at 12:00 UTC in Fig. 7 to the $10 \mathrm{~m}$ wind speeds in Fig. 6 would seem to suggest that the configuration of the low-level wind seen in MNH-ARP is necessary to have a correct localisation of the observed rainfall pattern over the Bisagno basin, due to it having the most accurate rainfall distribution. However, the rainfall accumulations which occurred at 12:00 UTC to the west of Bisagno (displayed in Fig. 3, middle panel) are most accurately simulated by WRF-NMM (Fig. 7a).

\subsubsection{Ensemble simulations}

Ensemble simulations were constructed for this case using the AROME and Meso-NH models in the configurations detailed in Sect. 3 (details and labelling of Meso-NH ensembles are recalled in Table 2). The $24 \mathrm{~h}$ accumulations for each of the members of the AROME ensemble displayed in Fig. 8 demonstrate that the introduced perturbations have limited success in correcting the displacement of the simulated rainfall west of the Bisagno region, despite proposing signifi- cantly different scenarios. Only member 6 (Fig. 8f) gives any significant accumulations over the hydrological basin of Bisagno. The other ensemble members, like the AROME CTRL simulation (Fig. 5), display the convective accumulations to the west of Bisagno.

A comparison between a Meso-NH (MNH-ARP-CT) and an AROME ensemble over the Bisagno watershed zone is displayed in Fig. 9. The two time series plots show that for the AROME ensemble, none of the members succeed in simulating the accumulations observed for this case, especially for the precipitation peak at 12:00 UTC. The AROME members do perform better than the Meso-NH members with regards to the precipitation peak around 02:00 UTC. The members of the Meso-NH ensemble over-predict the rainfall intensity for this peak, but do succeed in capturing the most intense peak at 12:00 UTC, albeit with a time delay of $1 \mathrm{~h}$ compared to the observations. The $24 \mathrm{~h}$ accumulations for the members of the Meso-NH ensemble also outperform the AROME members' accumulations. 


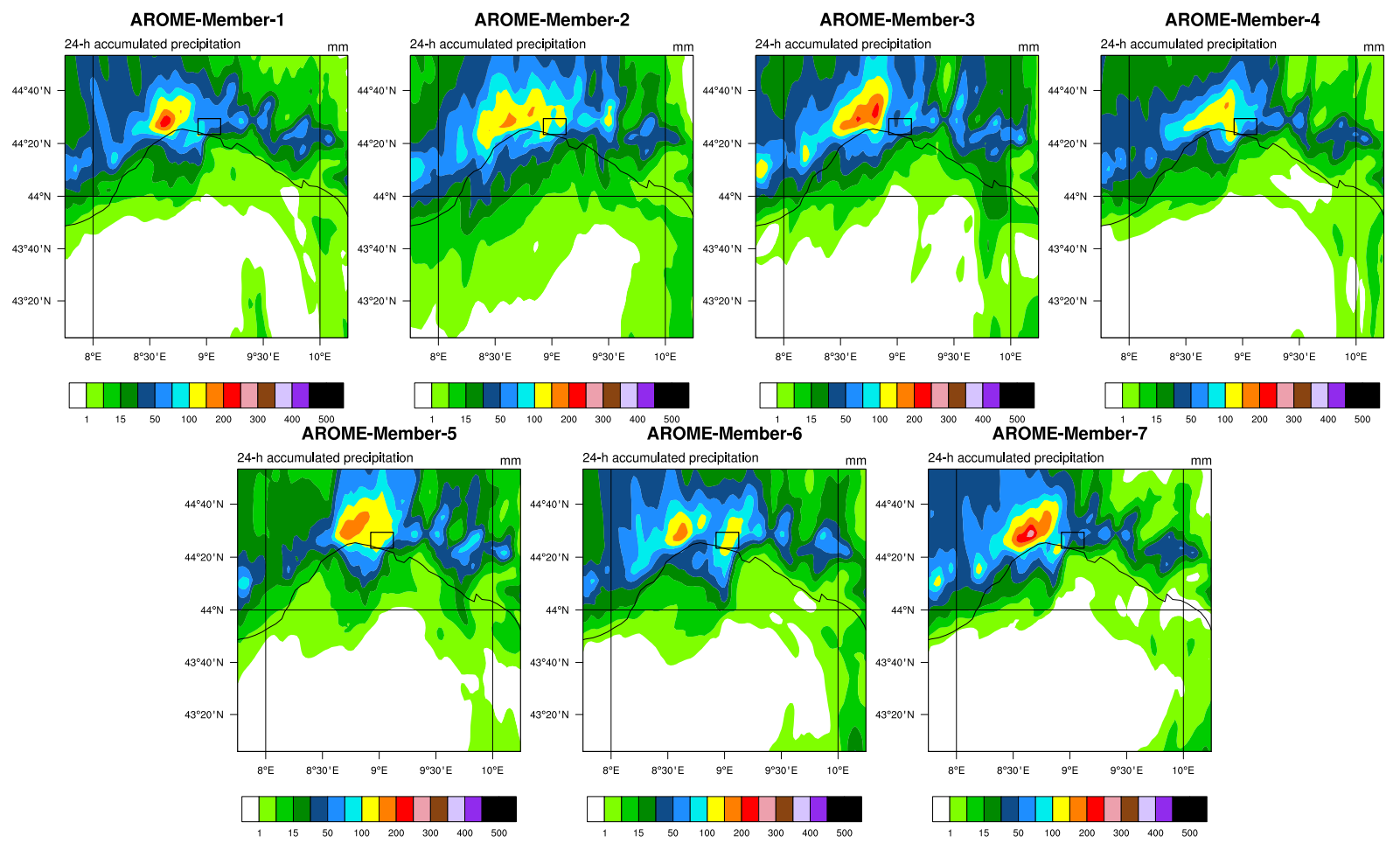

Figure 8. The $24 \mathrm{~h}$ simulated rainfall amounts (in $\mathrm{mm}$ ) of the 7 members of the AROME ensemble between 00:00 UTC on 4 November and 00:00 UTC on 5 November.

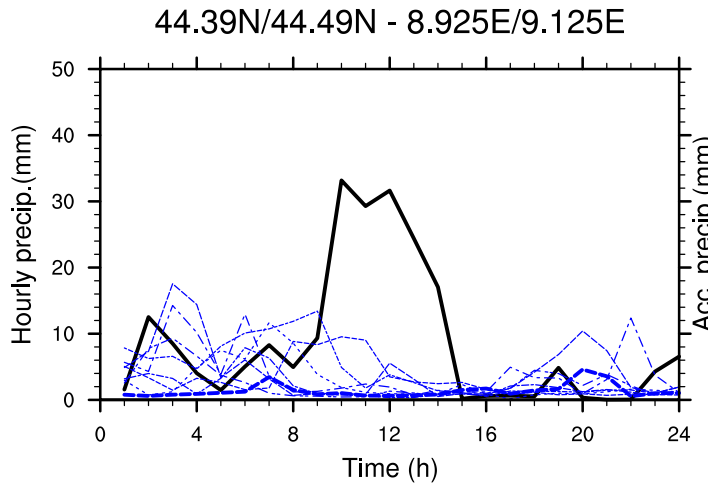

$44.39 \mathrm{~N} / 44.49 \mathrm{~N}-8.925 \mathrm{E} / 9.125 \mathrm{E}$

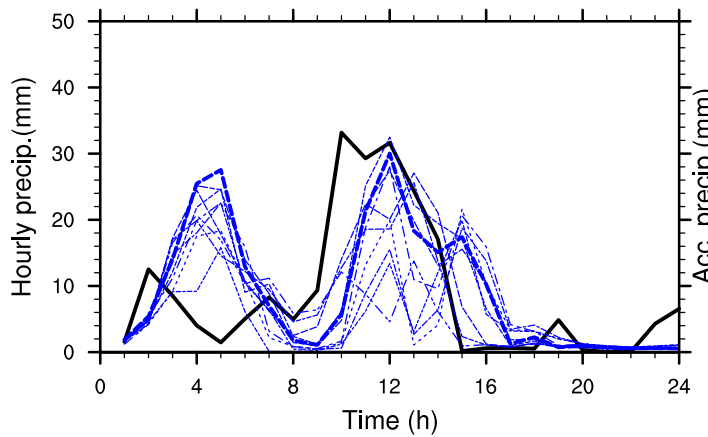

44.39N/44.49N - 8.925E/9.125E

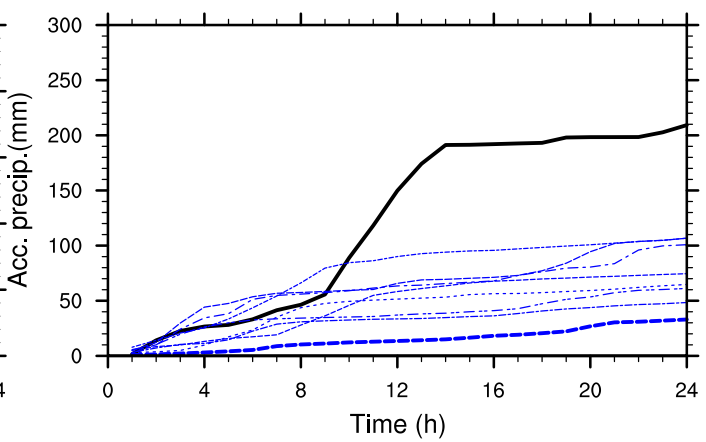

44.39N/44.49N - 8.925E/9.125E

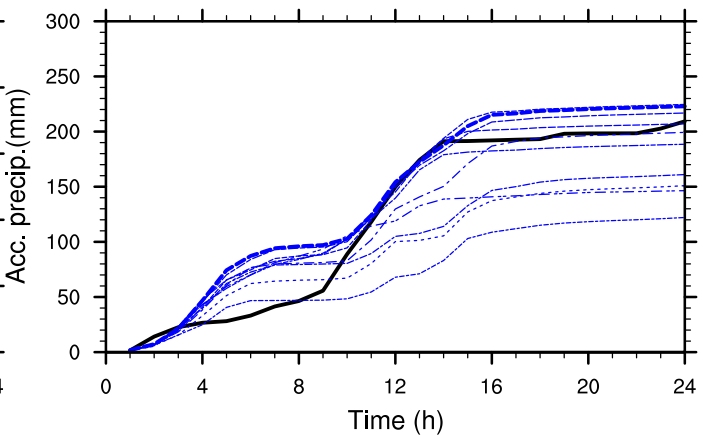

Figure 9. The temporal evolution of the $1 \mathrm{~h}$ accumulated simulated rainfall (left panels) and $24 \mathrm{~h}$ accumulated simulated rainfall (right panels) for the members of the AROME ensemble (top panels) and the members of the MNH-ARP-CT ensemble (bottom panels), over the Bisagno basin. The evolution of the observed rainfall is represented by the solid black line while the ensemble members appear in blue. The thickest blue line represents the evolution of the CTRL member of each ensemble. 
Table 2. Characteristics and labelling of Meso-NH ensembles performed for the case of 4 November 2011. The ensemble MNH-MWF-MT was not used to perform hydrological experiments. Differences between this and the MNH-MWF-CT ensemble were used to underline the influence of the microphysical processes.

\begin{tabular}{lllc}
\hline Ensemble name & IC and BC & Processes perturbed & Number of members \\
\hline MNH-ARP-CT-(0-9) & ARPEGE & Microphysical cold and turbulence & 10 \\
MNH-MWF-CT-(0-9) & IFS & Microphysical cold and turbulence & 10 \\
MNH-MWF-MT-(0-9) & IFS & Microphysical warm, cold and turbulence & 10 \\
\hline
\end{tabular}
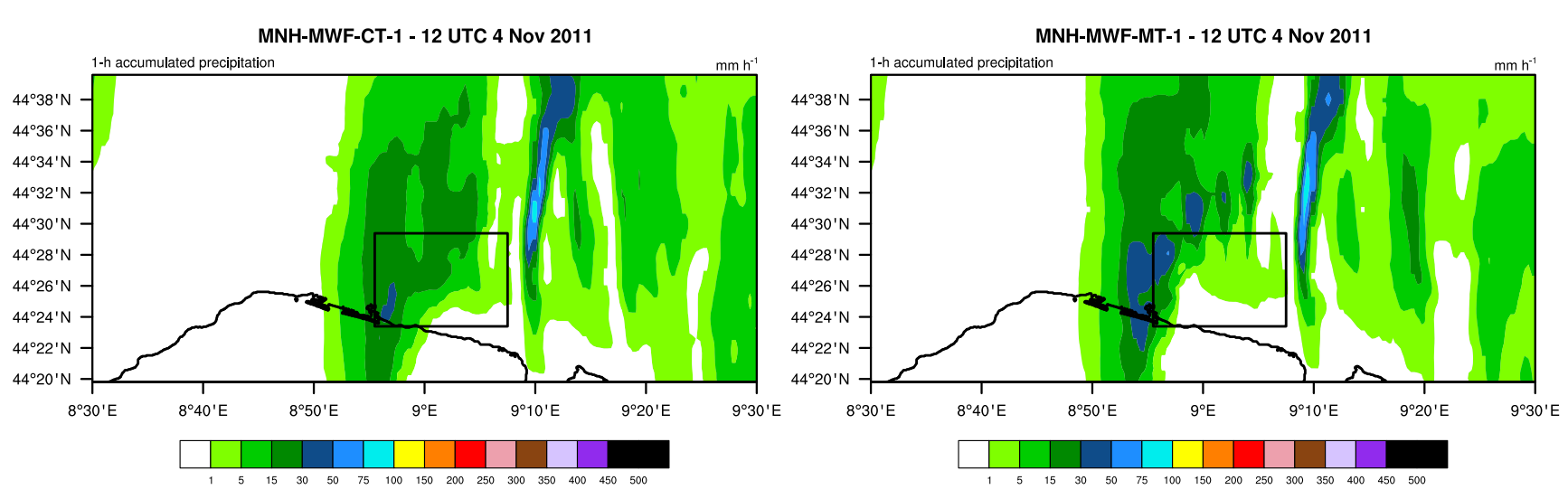

Figure 10. The $1 \mathrm{~h}$ simulated rainfall amounts (in mm) for the MNH-MWF-CT-1 and MNH-MWF-MT-1 ensemble members at 12:00 UTC on 4 November.

The Meso-NH ensembles were performed with perturbed physical processes, as described in Hally et al. (2014a, b). This permitted an evaluation of the contribution of certain physical processes to the development and organisation of the convective cells. Specifically, the microphysical warm and cold processes, along with the turbulence processes, were stochastically perturbed (an explanation of the ensemble notation and the processes perturbed in each ensemble is given in Table 2). Figure 10 displays a comparison of the $1 \mathrm{~h}$ simulated accumulated rainfall at 12:00 UTC for a member of the MNH-MWF-CT ensemble and a member of the MNH-MWF-MT ensemble.

A difference in rainfall accumulations over the Bisagno basin exists between the two simulations. The MNH-MWFMT-1 simulation displays a less intense area of rainfall compared to the MNH-MWF-CT-1 simulation while also presenting a displacement in the rainfall position to the west, and to the north. Plots of the simulated $2 \mathrm{~m}$ virtual potential temperature in Fig. 11 show that for the MNH-MWF-CT-1 simulation, there is a larger zone of cold air at the surface than for the MNH-MWF-MT-1 simulation. This is due to a perturbation factor of 0.6 applied to the time tendency of the rain evaporation process for the MNH-MWF-MT-1 simulation. Decreasing the rate of evaporation of rain droplets directly impacts upon the size of the low-level cold pool, as the process of the evaporation of raindrops removes heat from the surroundings (Bresson et al., 2009; Ducrocq et al., 2008). Figure 11 also illustrates the effect of the perturba- tions on the temperature gradient within the Bisagno zone. The MNH-MWFCT-1 member displays a stronger gradient than the MNH-MWF-MT-1 member. The gradient of the former also extends towards the coast while that of the latter is pushed northwards. This change in the mass of cold air disrupts the low-level convergence and thus leads to the aforementioned decrease in convective rainfall intensity and northward shift in rainfall localisation.

The same series of plots for a precipitation peak at 19:00 UTC demonstrate that the rainfall accumulations and the values of the $2 \mathrm{~m}$ virtual potential temperature are quite similar (not shown), indicating a smaller role played by the microphysical processes for this peak in precipitation and thus an increased contribution from other sources such as the large-scale conditions.

Overall, the ensemble simulations performed for this case clearly illustrate the uncertainty which can exist when simulating heavy precipitation events. This underlines the need to have as much information as possible available in order to correctly predict associated hydrological responses.

\subsection{Hydrological scenarios}

The RIBS, DRiFt and HBV models were run for the Bisagno basin, using all rainfall sources available i.e. rain gauges and meteorological models. The objective of this analysis was to verify the added value provided by the DRIHM infrastructure in the evaluation of the ability of meteorological mod- 

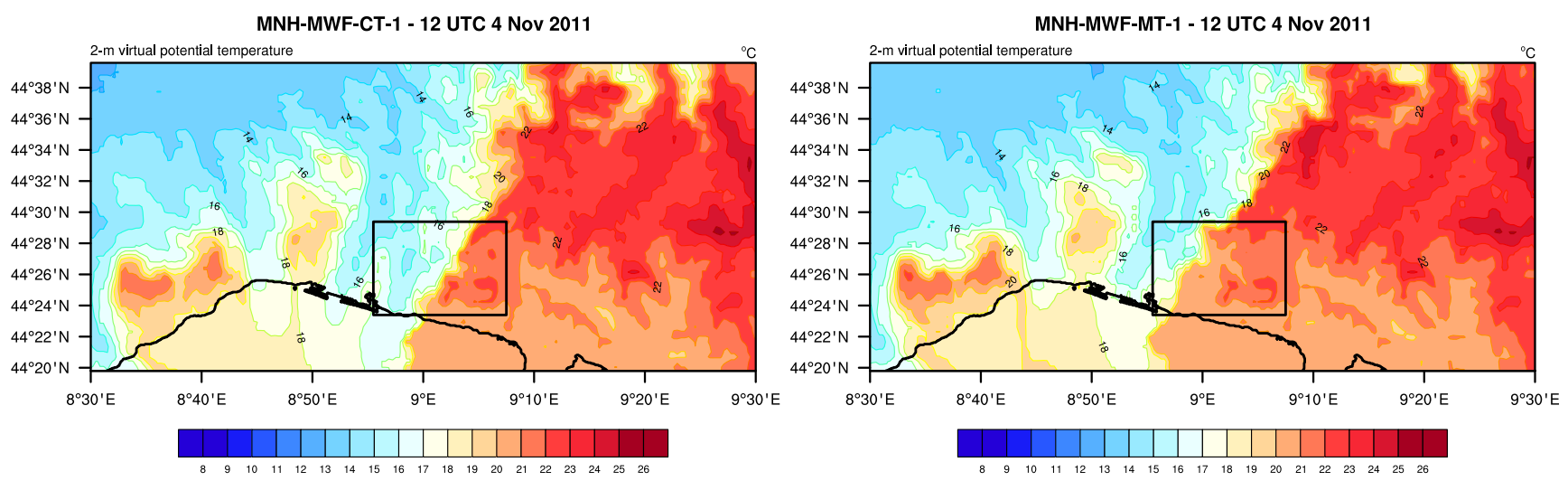

Figure 11. The simulated $2 \mathrm{~m}$ virtual potential temperature (in ${ }^{\circ} \mathrm{C}$ ) for the MNH-MWF-CT-1 and MNH-MWF-MT-1 ensemble members at 12:00 UTC on 4 November.
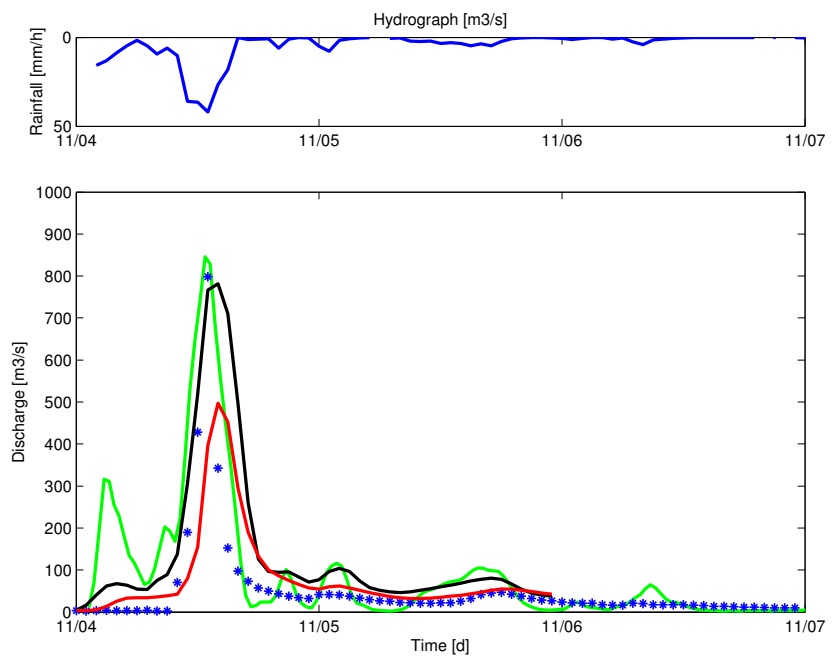

Figure 12. Solid lines represent the result of the simulations forced with observed rainfall for the episode of 4 November for RIBS (green), DRiFt (black) and HBV (red) models. Observations at the Passerella Firpo gauging station are represented by blue dots, while average rainfall over the basin is represented by the solid blue line in the upper plot. Observations and simulations are represented with a temporal resolution of $1 \mathrm{~h}$.

els to provide assistance to civil protection officials in predicting the event before the occurrence of rainfall. The time lapse between the occurrence of rainfall and the peak flow is very short, and a prediction of the peak based on modelled rainfall could greatly help decision makers. In this sense, the most relevant aspect is to predict the occurrence of an episode where significant flows are expected; accuracy in the quantitative prediction of peak flow is of less importance. This is due to the fact that in the context of early warning the main concern is the detection of a potentially dangerous event to properly organise civil defence activities. At an early stage of storm development the analysis is based on precipitation forecasts from different models and therefore large uncer- tainties may be expected on the exact location and amount of predicted rainfall thus preventing an accurate prediction of peak flow.

The three hydrological models were run for the episode occurring from 00:00 UTC on 4 November until 00:00 UTC on 5 November. DRiFt and HBV were run in deterministic mode while RIBS was run both in deterministic and probabilistic modes. Simulations performed with RIBS, DRiFt and HBV are summarised in Table 1. Rain sources correspond to the meteorological modelling experiments described in the previous section. For each rain source RIBS, DRiFt and HBV models were run in deterministic mode with the best parameter set and the RIBS model was run in probabilistic mode with an ensemble of 30 members, sampling model parameters from normal distributions centred on the values of the best parameter set. Since in the available calibration data there were only two significant episodes (6 November 1997 and 4 November 2011), the standard deviation of the optimal model parameters was relatively small, and therefore the spread provided by the probabilistic simulations is also correspondingly small.

\subsubsection{Simulations from rain-gauge observations}

RIBS, DRiFt and HBV results for the simulation with rain gauge observed rainfall are shown in Fig. 12 compared to streamflow observations at the Passerella Firpo gauging station, which registered a peak discharge of approximately $800 \mathrm{~m}^{3} \mathrm{~s}^{-1}$. The plot begins at 00:00 UTC on 4 November. Both RIBS and DRiFt models are able to predict the peak flow with $95 \%$ accuracy, while HBV underpredicts the peak flow. All three models illustrate quite accurately the timing of the peak flow, although their performance is worse in terms of flow volume because all models overestimate the volume of the central part of the hydrograph. RIBS also presents problems with the response to the initial rainfall in the episode. The gauging station did not start recording significant flows until 11:00 UTC, while the RIBS model re- 

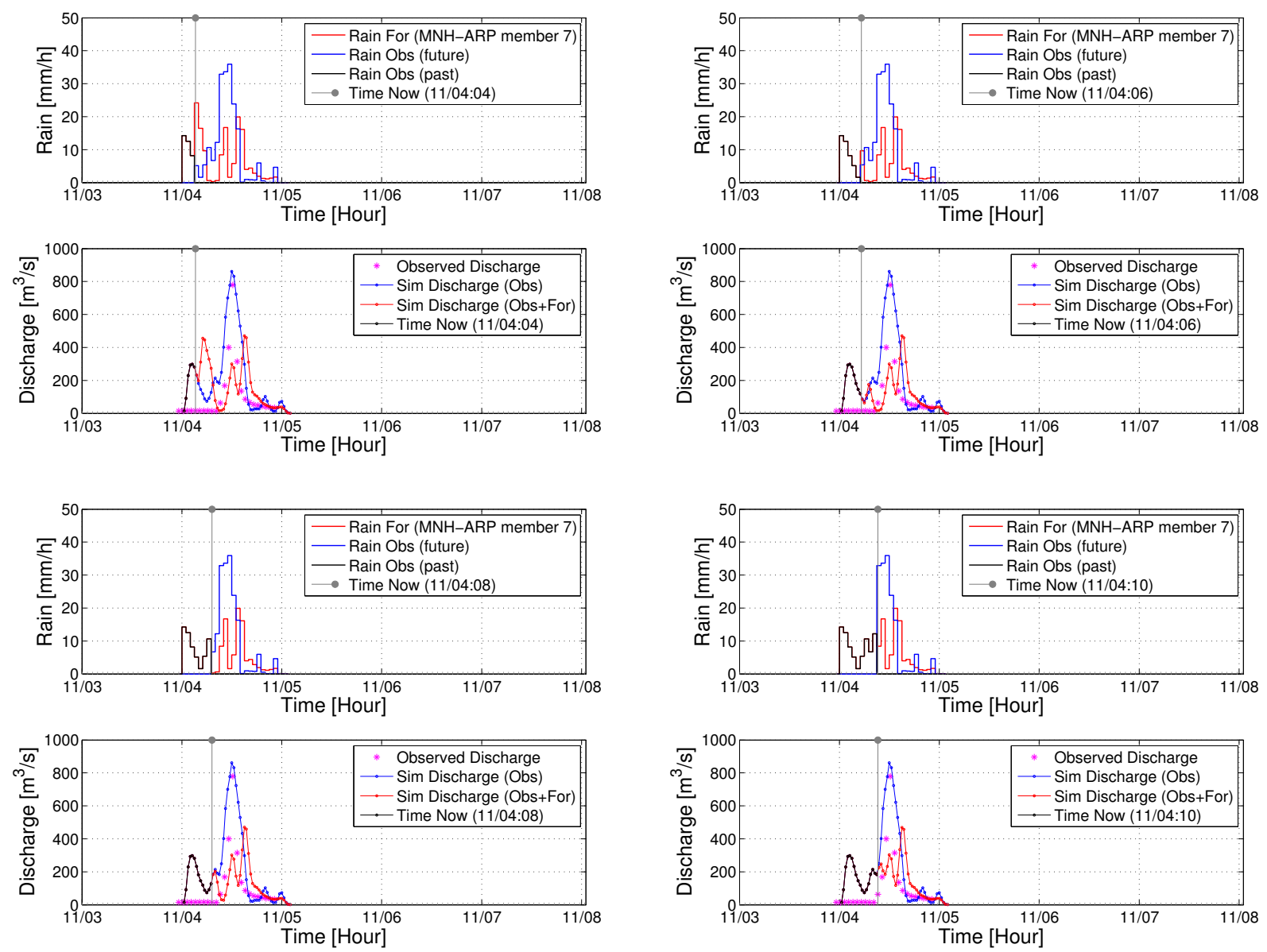

Figure 13. Emulation of real-time forecasting mode, combining observed rainfall and modelled rainfall. The RIBS model is forced with observed rainfall until current time and forecasted rainfall from one of the Meso-NH ensemble members. Four time steps are presented: at 04:00 UTC (upper left panel), at 06:00 UTC (upper right panel), at 08:00 UTC (lower left panel) and at 10:00 UTC (lower right panel).

sponse starts much earlier. This behaviour is repeated for two rainfall pulses that occur after the peak flow. DRiFt and HBV models show much better behaviour in modelling initial infiltration and in the receding limp of the hydrograph.

\subsubsection{Simulations from rainfall forecasts}

With the above-mentioned goal in mind, the models were run with observed rainfall up to a current time and with modelled rainfall for future times, as shown in Fig. 13 for the RIBS model. The comparison between observed discharge, simulated discharge with observed rainfall and simulated discharge with simulated rainfall allows an evaluation of the predictive skill of the hydrometeorological chain.

In this section, the performance of the meteorological models is analysed based on their capability to predict a flash flood event. The analysis is presented for the forecasts performed at 00:00 UTC on 4 November, using the rainfall produced by the meteorological models. A hypothetical early warning system with a warning threshold corresponding to $300 \mathrm{~m}^{3} \mathrm{~s}^{-1}$ in the Passerella Firpo gauging station is con- sidered. The decision to issue a flood warning for the following day (in this hypothetical situation, the following day signifies 4 November) is based on the results obtained in all simulations. Figure 14 illustrates the analysis for the simulation with the MNH-MWF ensemble. The solid lines represent the estimation of the probability distribution of peak discharge for 4 November, estimated from peak flows obtained in the simulations performed with all models forced with the MNH-MWF ensemble. RIBS was run both in deterministic and probabilistic modes, while DRiFt and HBV were run in deterministic mode. The differences in behaviour of the four rainfall-runoff simulation models are apparent. RIBS simulations, both in deterministic and probabilistic modes, produce higher peak flows than the DRiFt and HBV models. However, the difference between running RIBS in its deterministic and probabilistic modes is quite small. The perturbations introduced to run RIBS in its probabilistic mode were taken from the probability distribution of the $f, C_{v}$ and $K_{v}$ variables. This probability distribution was based upon values used in previous case studies. Given that only one previous 


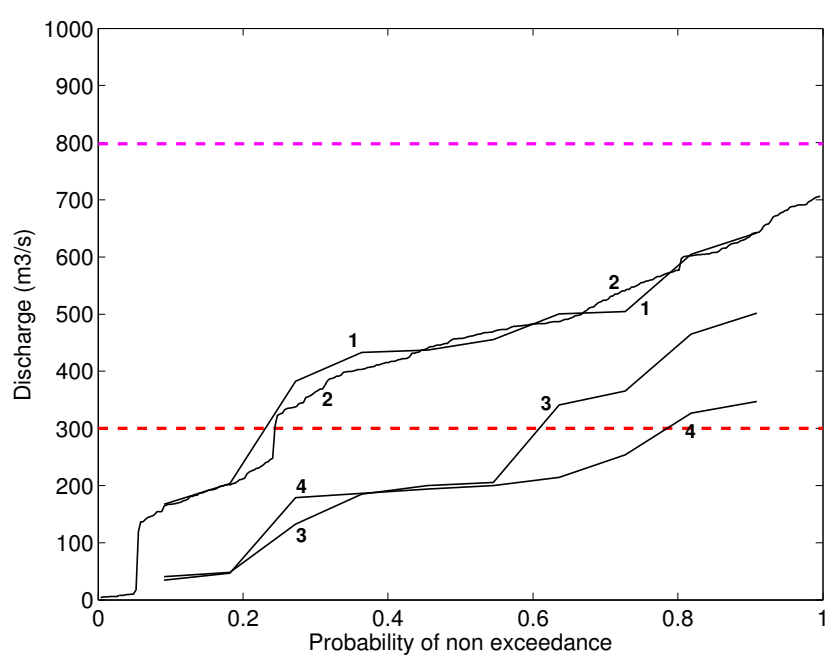

Figure 14. Flood risk analysis based on the simulation of rainfall runoff models forced with the MNH-MWF ensemble. The solid lines represent the estimation of the probability distribution of peak discharge for the four models: RIBS deterministic (1), RIBS probabilistic (2), DRiFt deterministic (3) and HBV deterministic (4). The dashed red line is the warning threshold and the dashed magenta line corresponds to the observed peak discharge.

case study was used in calculating the probability distribution, this explains the weak response to the introduced perturbations. Overall, the simulations fail to reproduce the observed peak flow of approximately $800 \mathrm{~m}^{3} \mathrm{~s}^{-1}$, but the global analysis of the full hydrometeorological chain allows the detection of a potentially dangerous situation, since the probabilities of exceeding the warning level of $300 \mathrm{~m}^{3} \mathrm{~s}^{-1}$ are relevant for all four models, being less probable for the HBV model than the other three.

Global results obtained for all models are presented in Fig. 15, where the estimations of the probability distributions of expected peak flows are shown for all meteorological models. In general, the difference between meteorological model ensembles is larger than the difference between rainfall-runoff model simulations. This indicates that the uncertainty on the rainfall is larger than the uncertainty on the rainfall-runoff model formulations. Although the predicted peak discharges are lower than observed, there are two meteorological model ensembles (MNH-ARP and MNH-MWF) that are able to predict a significant probability of exceeding the flooding threshold for the four hydrological models analysed. The RainFARM ensemble only predicts flooding for the two versions of the RIBS model, as is the case for the WRF-ARW and AROME models. The meteorological scenario provided by the WRF-NMM model does not produce flooding with any of the models. The overall situation depicted by the collection of model ensembles suggests that the meteorological situation is potentially dangerous, providing the decision maker with enough evidence to issue a warning that could reduce property damage.

\section{Conclusions}

The DRIHM project aimed to develop a prototype e-Science environment which provides easy access to hydrometeorological data and models and also facilitates collaboration between meteorologists, hydrologists and Earth science experts in order to accelerate scientific advances in hydrometeorological research (HMR). In this paper, a description of how HMR can exploit the DRIHM infrastructure was presented, which theoretically allows the composition of any meteorological model with any hydrological model through the use of the MMB. The flash flood case of 4 November 2011 in Genoa, Italy, was simulated using this environment. Five different atmospheric models were coupled with three hydrological models, some of them being run as ensembles, thus providing an unprecedented set of likely hydrometeorological scenarios.

Throughout this study, the many different uses of such a data set have been presented. For small-scale basins such as the Bisagno catchment, forecasting precipitation at the right location is a tedious task. The convergence line which led to the heavy precipitation over Genoa was demonstrated to be quite predictable (Fiori et al., 2014; Buzzi et al., 2014). However, in the simulations outlined in this study, it was found that only a small subset of the available simulations (namely, those based on Meso-NH) was able to correctly predict the localisation of the observed rainfall over the Bisagno watershed, while none of the simulations correctly predicted the rainfall intensity. It must also be noted, however, that simulations other than those based on Meso-NH were superior in simulating other aspects, thus highlighting the need for multi-model simulations.

Another important feature of the DRIHM infrastructure, the MMB, considerably eased model inter-comparisons by providing a common interface format. This enabled distinctive features crucial to the correct prediction of rainfall accumulations to be isolated (e.g. the configuration of the lowlevel wind over the Ligurian Sea). In a more general context, such comparisons can also help to shed light on systematic model or ensemble deficiencies. However, an application of this kind would require more case studies than the single situation presented within this study.

The multi-model simulations carried out through the DRIHM e-Science environment allowed sensitivity studies to different sources of modelling error to be conducted. These are quite useful in understanding model uncertainties and how they propagate through hydrometeorological forecasting chains. In future studies, these uncertainties could be targeted by integrating improved observational data sets which compensate for the uncertainties and/or by the use of corrected or modified physical parameterisations.

It has been found that the sensitivity to the hydrological model used to predict discharges at the outlet of the Bisagno watershed is significant. However, the sensitivity to the source of forecasted rainfall used to drive the hydrological 

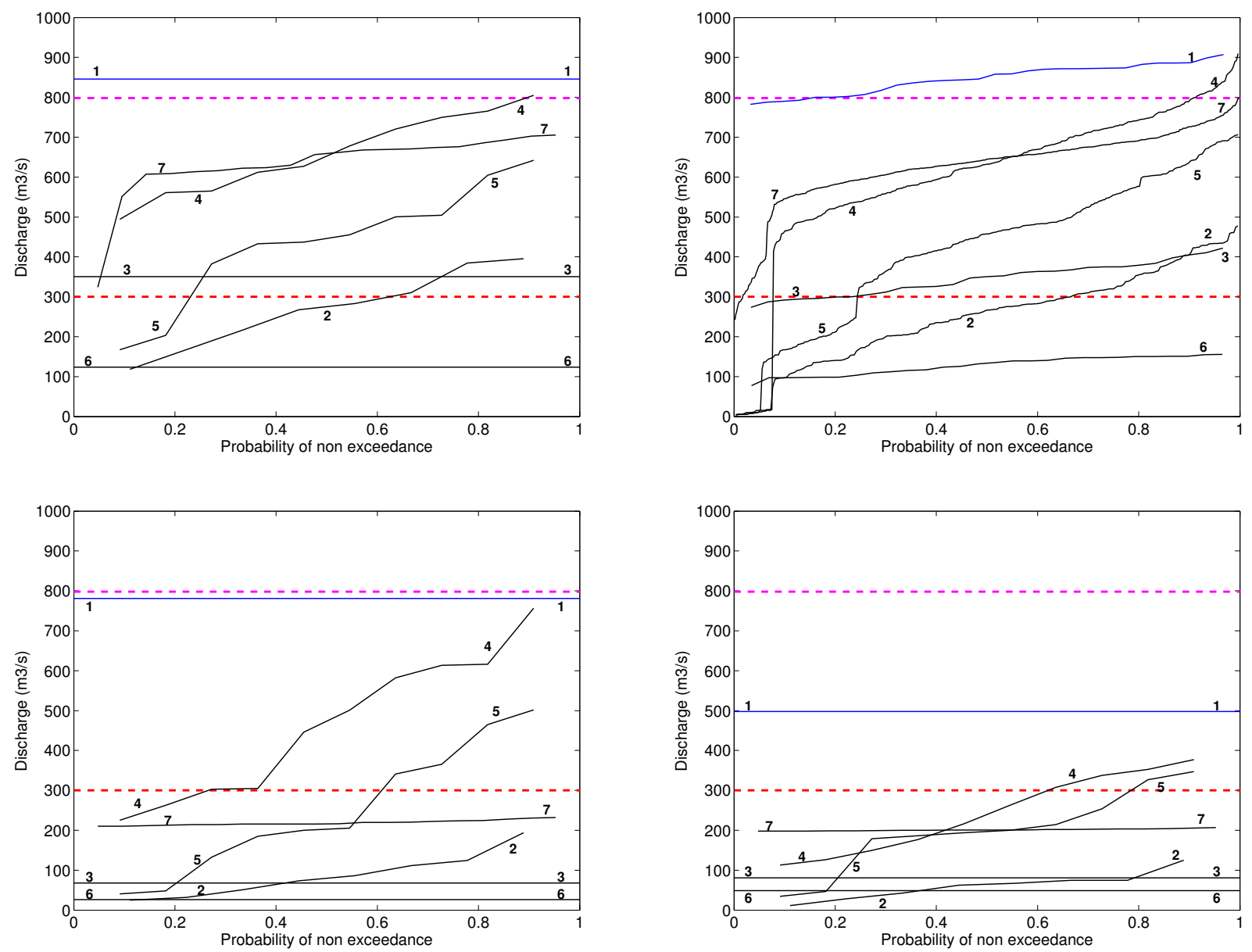

Figure 15. Summary of all results obtained with all hydrological models forced by all meteorological models. The solid line represents the estimation of the probability distribution of peak discharge for (1) observed rainfall, (2) AROME, (3) WRF-ARW, (4) MNH-ARP, (5) MNH-MWF, (6) WRF-NMM and (7) RainFARM. The red dashed line is the warning threshold and the dashed magenta line corresponds to the observed peak discharge. The upper left plot shows results for the RIBS deterministic simulation, the upper right plot results for the RIBS probabilistic simulation, the lower left plot results for a DRiFt deterministic simulation and the lower right plot results for an HBV deterministic simulation.

models has been found to be even greater. In the context of a flash flood early warning system, the analysis of the set of hydrometeorological simulations presented here would have indicated a substantial risk of flash flooding.

The use of the DRIHM e-Science environment has been exemplified for one case study only and for a limited set of applications, i.e. the coupling of meteorological models with rainfall-discharge models for flash flood hydrometeorological forecasting. However, other case studies, such as the flash flood that occurred in the Muga catchment on 6 November 2011 and the more recent floods in Serbia and Bosnia and Herzegovina in May 2014 are already under investigation. These will be reported upon in further publications. Work is also ongoing on the use of hydrometeorological chains such as those demonstrated in this article to initialise hydraulic models with the ultimate aim of estimating the water level, flow, and impact of flash floods locally. Finally, through the extensibility of the DRIHM e-Science environment, it is expected that additional models will be supported in the future and that it will attract interest from other Earth sciences for the benefit of innovative cross-disciplinary studies.

Acknowledgements. The authors would like to acknowledge the support of the DRIHM (Distributed Research Infrastructure for Hydro-Meteorology, 2011-2015) project, funded within the European Union's Seventh Framework Programme for research, technological development and demonstration under grant agreement no. RI-283568. The Italian authors are also grateful for the support provided by the Italian Civil Protection Department and the Regione Liguria. The authors also acknowledge Regione Liguria and Regione Piemonte for providing data from the regional meteorological observation networks, as well as the Italian Civil Protection Department and Jelena Marković for providing the Italian Radar Network data. 
Edited by: G. Panegrossi

\section{References}

Bell, T. L. and Kundu, P. K.: Comparing satellite rainfall estimates with rain gauge data: optimal strategies suggested by a spectral model, J. Geophys. Res., 108, 4121, doi:10.1029//2002JD002641, 2003.

Bénard, P.: On the use of a wider class of linear systems for the design of constant-coefficients semi-implicit time schemes in NWP, Mon. Weather Rev., 132, 1319-1324, 2004.

Bergström, S.: Development and application of a conceptual runoff model for Scandinavian catchments, Ph.D. thesis, Swedish Meteorological and Hydrological Institute (SMHI), Norköping, Sweden, 1976.

Betts, A. K. and Miller, M. J.: The representation of cumulus convection in numerical models, AMS Meteorol. Monogr., 24, 107121, 1993.

Bresson, R., Ricard, D., and Ducrocq, V.: Idealized mesoscale numerical study of Mediterranean heavy precipitating convective systems, Meteorol. Atmos. Phys., 103, 45-55, 2009.

Bubnová, R., Hello, G., Benard, P., and Geleyn, J. F.: Integration of the fully elastic equations cast in the hydrostatic-pressure terrainfollowing coordinate in the framework of the Arpege/Aladin NWP system, Mon. Weather Rev., 123, 515-535, 1995.

Buzzi, A., Davolio, S., Malguzzi, P., Drofa, O., and Mastrangelo, D.: Heavy rainfall episodes over Liguria in autumn 2011: numerical forecasting experiments, Nat. Hazards Earth Syst. Sci., 14, 1325-1340, doi:10.5194/nhess-14-1325-2014, 2014.

Chou, M. D. and Suarez, M. J.: A solar radiation parameterization for atmospheric studies, in: Technical Report Series on Global Modeling and Data Assimilation, edited by: Suarez, M. J., NASA/TM-1999-104606, Goddard Space Flight Center, Greenbelt, MD, 42 pp., 1999.

Cloke, H. L. and Pappenberger, F.: Ensemble flood forecasting: a review, J. Hydrol., 375, 613-626, doi:10.1016/j.jhydrol.2009.06.005, 2009.

Cuxart, J., Bougeault, P., and Redelsperger, J.-L.: A turbulence scheme allowing for mesoscale and large-eddy simulations, Q. J. Roy. Meteorol. Soc., 126, 1-30, 2000.

D’Agostino, D., Clematis, A., Galizia, A., Quarati, A., Danovaro, E., Roverelli, L., Zereik, G., Kranzlmueller, D., Schiffers, M., gentschen Felde, N., Straube, C., Caumont, O., Richard, E., Garrote, L., Harpham, Q., Jagers, H. R. A., Dimitrijevic, V., Dekic, L., Fiori, E., Delogu, F., and Parodi, A.: The DRIHM project: a flexible approach to integrate HPC, grid and cloud resources for hydro-meteorological research, in: Proc. Int. Conf. for High Performance Computing, Networking, Storage, and Analysis (SC14), abstract pap 377, New Orleans, LA, in press, 2014.

Danovaro, E., Roverelli, L., Zereik, G., Galizia, A., D’Agostino, D., Quarati, A., Clematis, A., Delogu, F., Fiori, E., Parodi, A., Straube, C., Felde, N., Harpham, Q., Jagers, B., Garrote, L., Dekic, L., Ivkovic, M., Richard, E., and Caumont, O.: Setup an hydro-meteo experiment in minutes: the DRIHM e-infrastructure for hydro-meteorology research, in: Proc. 10th IEEE Int. Conf.
eScience (IEEE eScience 2014), abstract 79, Guarujá, Brazil, in press, 2014.

Davolio, S., Miglietta, M. M., Diomede, T., Marsigli, C., and Montani, A.: A flood episode in northern Italy: multi-model and single-model mesoscale meteorological ensembles for hydrological predictions, Hydrol. Earth Syst. Sci., 17, 2107-2120, doi:10.5194/hess-17-2107-2013, 2013.

Descamps, L., Labadie, C., Joly, A., Bazile, E., Arbogast, P., and Cébron, P.: PEARP, the Météo-France short-range ensemble prediction system, Q. J. Roy. Meteor. Soc., doi:10.1002/qj.2469, 2014.

Ducrocq, V., Nuissier, O., Ricard, D., Lebeaupin, C., and Thouvenin, T.: A numerical study of three catastrophic precipitating events over southern France, II: Mesoscale triggering and stationarity factors, Q. J. Roy. Meteorol. Soc., 134, 131-145, 2008.

Fiori, E., Comellas, A., Molini, L., Rebora, N., Siccardi, F., Gochis, D. J., Tanelli, S., and Parodi, A.: Analysis and hindcast simulations of an extreme rainfall event in the Mediterranean area: The Genoa 2011 case, Atmos. Res., 138, 13-29, doi:10.1016/j.atmosres.2013.10.007, 2014.

Gal-Chen, T. and Somerville, R.: On the use of a coordinate transformation for the solution of the Navier-Stokes equations, J. Comput. Phys., 17, 209-228, doi:10.1016/0021-9991(75)900376,1975 .

Galizia, A., D’Agostino, D., Quarati, A., Zereik, G., Roverelli, L., Danovaro, E., Clematis, A., Fiori, E., Delogu, F., Parodi, A., Straube, C., Felde, N., Schiffers, M., Kranzlmueller, D., Harpham, Q., Jagers, B., Garrote, L., Dimitrijevic, V., Dekic, L., Caumont, O., and Richard, E.: Towards an interoperable and distributed e-Infrastructure for Hydro-Meteorology: the DRIHM project, in: Proc. 7th International Congress on Environmental Modelling and Software, International Environmental Modelling and Software Society (iEMSs), San Diego, CA, available at: http://www.iemss.org/society/index. php/iemss-2014-proceedings, last access: 13 August 2014.

Garrote, L. and Bras, R. L.: A distributed model for real-time flood forecasting using digital elevation models, J. Hydrol., 167, 279 306, 1995a.

Garrote, L. and Bras, R. L.: An integrated software environment for real-time use of a distributed hydrologic model, J. Hydrol., 167, 307-326, 1995 b.

Giannoni, F., Roth, G., and Rudari, R.: A semi-distributed rainfallrunoff model based on a geomorphologic approach, Phys. Chem. Earth B, 25, 665-671, 2000.

Giannoni, F., Roth, G., and Rudari, R.: A procedure for drainage network identification from geomorphology and its application to the prediction of the hydrologic response, Adv. Water Resour., 28, 567-581, 2005.

Giannoni, F., Roth, G., and Rudari, R.: The value of the Italian civil protection system in integrated water management for the Mediterranean environment, Integr. Water Manage., 80, 33-49, 2008.

Hally, A., Richard, E., and Ducrocq, V.: An ensemble study of HyMeX IOP6 and IOP7a: sensitivity to physical and initial and boundary condition uncertainties, Nat. Hazards Earth Syst. Sci., 14, 1071-1084, doi:10.5194/nhess-14-1071-2014, 2014a.

Hally, A., Richard, E., Fresnay, S., and Lambert, D.: Ensemble simulations with perturbed physical parameterisations: Pre- 
HyMeX case studies, Q. J. Roy. Meteorol. Soc., 140, 1900-1916, doi:10.1002/qj.2257, 2014b.

Hong, S. Y., Noh, Y., and Dudhia, J.: A new vertical diffusion package with an explicit treatment of entrainment processes, Mon. Weather Rev., 134, 2318-2341, doi:10.1175/mwr3199.1, 2006.

Houtekamer, P., Lefaivre, L., Derome, J., Ritchie, H., and Mitchell, H.: A system simulation approach to ensemble prediction, Mon. Weather Rev., 124, 1225-1242, 1996.

Janjic, Z. I.: The step-mountain eta coordinate model - further developments of the convection, viscous sublayer, and turbulence closure schemes, Mon. Weather Rev., 122, 927-945, 1994.

Janjic, Z. I.: The Mellor-Yamada level 2.5 scheme in the NCEP Eta Model, in: Eleventh Conference on Numerical Weather Prediction, American Meteorological Society, Norfolk, VA, USA, 333334, 1996a.

Janjic, Z. I.: The Surface Layer in the NCEP Eta Model, in: Eleventh Conference on Numerical Weather Prediction, American Meteorological Society, Norfolk, VA, USA, 354-355, $1996 \mathrm{~b}$.

Janjic, Z. I., Gerrity Jr, J. P., and Nickovic, S.: An alternative approach to nonhydrostatic modeling, Mon. Weather Rev., 129, 1164-1178, 2001.

Janjic, Z. I.: A nonhydrostatic model based on a new approach, Meteorol. Atmos. Phys., 82, 271-285, 2003.

Karssenberg, D., Schmitz, O., Salamon, P., De Jong, C., and Bierkens, M. F. P.: A software framework for construction of process-based stochastic spatiotemporal models and data assimilation, Environ. Model. Softw., 25, 1-14, doi:10.1016/j.envsoft.2009.10.004, 2009.

Lafore, J. P., Stein, J., Asencio, N., Bougeault, P., Ducrocq, V., Duron, J., Fischer, C., Héreil, P., Mascart, P., Masson, V., Pinty, J. P., Redelsperger, J. L., Richard, E., and VilàGuerau de Arellano, J.: The Meso-NH Atmospheric Simulation System, Part I: adiabatic formulation and control simulations, Ann. Geophys., 16, 90-109, doi:10.1007/s00585-997-0090-6, 1998.

Lanza, L. G.: A conditional simulation model of intermittent rain fields, Hydrol. Earth Syst. Sci., 4, 173-183, doi:10.5194/hess-4173-2000, 2000.

Lascaux, F., Richard, E., and Pinty, J.-P.: Numerical simulations of three different MAP IOPs and the associated microphysical processes, Q. J. Roy. Meteor. Soc., 132, 1907-1926, 2006.

Lindstrom, G., Johansson, B., Persson, M., Gardelin, M., and Bergstrom, S.: Development and test of the distributed HBV-96 hydrological model, J. Hydrol., 201, 272-288, 1997.

Llasat, M. C., Llasat-Botija, M., Petrucci, O., Pasqua, A. A., Rosselló, J., Vinet, F., and Boissier, L.: Towards a database on societal impact of Mediterranean floods within the framework of the HYMEX project, Nat. Hazards Earth Syst. Sci., 13, 13371350, doi:10.5194/nhess-13-1337-2013, 2013.

Masson, V.: A physically-based scheme for the urban energy budget in atmospheric models, Bound.-Lay. Meteorol., 94, 357-397, 2000.

Matheron, G.: The intrinsic random functions and their applications, Adv. Appl. Probab., 5, 439-468, 1973.

Mediero, L., Garrote, L., and Martin-Carrasco, F. J.: Probabilistic calibration of a distributed hydrological model for flood forecasting, Hydrol. Sci. J., 56, 1129-1149, 2011.

Mediero, L., Garrote, L., and Chavez-Jimenez, A.: Improving probabilistic flood forecasting through a data assimilation scheme based on genetic programming, Nat. Hazards Earth Syst. Sci., 12, 3719-3732, doi:10.5194/nhess-12-3719-2012, 2012.

Melone, F., Diomede, T., Perucacci, S., Rossi, M., Ressarollo, A., and Verdecchia, M.: Review and selection of hydrological models - Integration of hydrological models and meteorological inputs, Resulting from Work Package 1, Action 13, RISK AWARE - INTERREG III B - CAD-SES, available at: http://www.smr. arpa.emr.it/riskaware/get.php?file=ReportWP1.13.pdf (last access: 13 August 2014), 2005.

Mlawer, E. J., Taubman, S. J., Brown, P. D., Iacono, M. J., and Clough, S. A.: Radiative transfer for inhomogeneous atmospheres: RRTM, a validated corrolated-k model for the longwave, J. Geophys. Res., 102, 16663-16682, 1997.

Molteni, F., Buizza, R., Palmer, T. N., and Petroliagis, T.: The ECMWF ensemble prediction system: methodology and validation, Q. J. Roy. Meteorol. Soc., 122, 73-119, 1996.

Niu, G. Y., Yang, Z. L., Mitchell, K. E., Chen, F., Ek, M. B., Barlage, M., Kumar, A., Manning, K., Niyogi, D., Rosero, E., Tewari, M., and Xia, Y. L.: The community Noah land surface model with multiparameterization options (Noah-MP): 1. Model description and evaluation with local-scale measurements, J. Geophys. Res., 116, D12109, doi:10.1029/2010jd015139, 2011.

Noilhan, J. and Mafhouf, J.: The ISBA land surface parameterisation, Global Planet. Change, 13, 145-159, 1996.

Nuissier, O., Joly, B., Vie, B., and Ducrocq, V.: Uncertainty of lateral boundary conditions in a convection-permitting ensemble: a strategy of selection for Mediterranean heavy precipitation events, Nat. Hazards Earth Sys. Sci., 12, 2993-3011, doi:10.5194/nhess-12-2993-2012, 2012.

Pappenberger, F., Beven, K. J., Hunter, N. M., Bates, P. D., Gouweleeuw, B. T., Thielen, J., and de Roo, A. P. J.: Cascading model uncertainty from medium range weather forecasts (10 days) through a rainfall-runoff model to flood inundation predictions within the European Flood Forecasting System (EFFS), Hydrol. Earth Syst. Sci., 9, 381-393, doi:10.5194/hess-9-3812005, 2005.

Pergaud, J., Masson, V., Malardel, S., and Couvreux, F.: A parameterization of dry thermals and shallow cumuli for mesoscale numerical weather prediction, Bound.-Lay. Meteorol., 132, 83106, 2009.

Pinty, J.-P. and Jabouille, P.: A mixed-phase cloud parameterization for use in a mesoscale non-hydrostatic model: simulations of a squall line and of orographic precipitations, in: Tenth AMS Cloud Physics Conference, American Meteorological Society, Everett, WA, USA, 217-220, 1998.

Price, D., Hudson, K., Boyce, G., Schellekens, J., Moore, R. J., Clark, P., Harrison, T., Connolly, E., and Pilling, C.: Operational use of a grid-based model for flood forecasting, P. I. Civil. Eng.Water, 165, 65-77, doi:10.1680/wama.2012.165.2.65, 2012.

Rakovec, O., Weerts, A. H., Hazenberg, P., Torfs, P. J. J. F., Uijlenhoet, R.: State updating of a distributed hydrological model with Ensemble Kalman Filtering: Effects of updating frequency and observation network density on forecast accuracy, Hydrol. Earth Syst. Sci., 16, 3435-3449, doi:10.5194/hess-16-34352012, 2012.

Rebora, N., Ferraris, L., von Hardenberg, J., and Provenzale, A.: RainFARM: rainfall downscaling by a filtered autoregressive model, J. Hydrometeorol., 7, 724-738, 2006. 
Rebora, N., Molini, L., Casella, E., Comellas, A., Fiori, E., Pignone, F., Siccardi, F., Silvestro, F., Tanelli, S., and Parodi, A.: Extreme rainfall in the mediterranean: what can we learn from observations?, J. Hydrometeorol., 14, 906-922, 2013.

Renner, M., Werner, M., Rademacher, S., and Sprokkereef, E.: Verification of ensemble flow forecasts for the River Rhine, J. Hydrol., 376, 463-475, 2009.

Ridler, M. E. N., van Velzen, S., Hummel, I., Sandholt, A., Falk, K., Heemik, A., and Madsen, H.: Data assimilation framework: Linking an open data assimilation library (OpenDA) to a widely adopted model interface (OpenMI), Environ. Model. Softw., 57, 76-89, doi:10.1016/j.envsoft.2014.02.008, 2014.

Rotach, M. W., Ambrosetti, P., Ament, F., Appenzeller, C., Arpagaus, M., Bauer, H. S., Behrendt, A., Bouttier, F., Buzzi, A., Corazza, M., Davolio, S., Denhard, M., Dorninger, M., Fontannaz, L., Frick, J., Fundel, F., Germann, U., Gorgas, T., Hegg, C., Hering, A., Keil, C., Liniger, M. A., Marsigli, C., McTaggart-Cowan, R., Montaini, A., Mylne, K., Ranzi, R., Richard, E., Rossa, A., Santos-Munoz, D., Schar, C., Seity, Y., Staudinger, M., Stoll, M., Volkert, H., Walser, A., Wang, Y., Werhahn, J., Wulfmeyer, V., and Zappa, M.: MAP D-PHASE real-time demonstration of weather forecast quality in the Alpine region, B. Am. Meteorol. Soc., 90, 1321-1336, doi:10.1175/2009bams2776.1, 2009.

Roth, G., LaBarbera, P., and Greco, M.: On the description of the basin effective drainage structure, J. Hydrol., 187, 119-135, 1996.

Schaake, J. C., Hamill, T. M., Buizza, R., and Clark, M.: The hydrological ensemble prediction experiment, B. Am. Meteorol. Soc., 88, 1541-1547, doi:10.1175/bams-88-10-1541, 2007.

Seity, Y., Brousseau, P., Malardel, S., Hello, G., Benard, P., Bouttier, F., Lac, C., and Masson, V.: The AROME - France convective-scale operational model, Mon. Weather Rev., 139, 976-991, 2011.
Silvestro, F., Rebora, N., and Ferraris, L.: Quantitative flood forecasting on small- and medium-sized basins: a probabilistic approach for operational purposes, J. Hydrometeorol., 12, 14321446, 2011.

Thielen, J., Bartholmes, J., Ramos, M.-H., and de Roo, A.: The European Flood Alert System - Part 1: Concept and development, Hydrol. Earth Syst. Sci., 13, 125-140, doi:10.5194/hess-13-1252009, 2009.

Thompson, G., Field, P. R., Rasmussen, R. M., and Hall, W. D.: Explicit forecasts of winter precipitation using an improved bulk microphysics scheme, Part II: Implementation of a new snow parameterization, Mon. Weather Rev., 136, 5095-5115, 2008.

Verkade, J. S., Brown, J., Reggiani, P., and Weerts, A. H.: Postprocessing ECMWF precipitation and temperature ensemble reforecasts for operational hydrologic forecasting at various spatial scales, J. Hydrol., 501, 73-91, doi:10.1016/j.jhydrol.2013.07.039, 2013.

Vié, B., Molinié, G., Nuissier, O., Vincendon, B., Ducrocq, V., Bouttier, F., and Richard, E.: Hydro-meteorological evaluation of a convection-permitting ensemble prediction system for Mediterranean heavy precipitating events, Nat. Hazards Earth Syst. Sci., 12, 2631-2645, doi:10.5194/nhess-12-2631-2012, 2012.

Vincendon, B., Ducrocq, V., Nuissier, O., and Vie, B.: Perturbation of convection-permitting NWP forecasts for flash-flood ensemble forecasting, Nat. Hazards Earth Sys. Sci., 11, 1529-1544, 2011.

Werner, M., Schellekens, J., Gijsbers, R., van Dijk, M., van den Akker, O., and Heynert, K.: The Delft-FEWS flow forecasting system, Environ. Modell. Softw., 40, 65-77, 2013.

Williams, D. N., Phillips, T. J., Hankin, S. C., and Middleton, D.: In Earth System Modelling, vol. 4, Springer, Berlin, Heidelberg, 2013. 